\title{
Lung carcinogenicity of inhaled multi- walled carbon nanotube in rats
}

\author{
Tatsuya Kasai*, Yumi Umeda, Makoto Ohnishi, Takashi Mine, Hitomi Kondo, Tetsuya Takeuchi, \\ Michiharu Matsumoto and Shoji Fukushima
}

\begin{abstract}
Background: Multi-walled carbon nanotubes (MWCNTs) constitute one of the most promising types of nanomaterials in industry today. With their increasing use, the potential toxicity and carcinogenicity of MWCNT needs to be evaluated in bioassay studies using rodents. Since humans are mainly exposed to MWCNT by inhalation, we performed a 104-week carcinogenicity study using whole-body inhalation exposure chambers with a fibrous straight type of MWCNT at concentrations of $0,0.02,0.2$, and $2 \mathrm{mg} / \mathrm{m}^{3}$ using male and female F344 rats.

Results: Lung carcinomas, mainly bronchiolo-alveolar carcinoma, and combined carcinomas and adenomas were significantly increased in males exposed to 0.2 and $2 \mathrm{mg} / \mathrm{m}^{3} \mathrm{MWNT}-7$ and in females exposed to $2 \mathrm{mg} / \mathrm{m}^{3} \mathrm{MWNT}-7$ compared to the clean air control group. However, no development of pleural mesothelioma was observed. Concentration-dependent toxic effects in the lung such as epithelial hyperplasia, granulomatous change, localized fibrosis, and alteration in BALF parameters were found in MWNT-7 treatment groups of both sexes. There were no MWNT-7-specific macroscopic findings in the other organs, including the pleura and peritoneum. Absolute and relative lung weights were significantly elevated in male rats exposed to 0.2 and $2 \mathrm{mg} / \mathrm{m}^{3} \mathrm{MWNT}-7$ and in all exposed female groups. The lung burdens of MWNT-7 were clearly increased in a concentration-dependent as well as a durationdependent manner.
\end{abstract}

Conclusion: There is clear evidence that MWNT-7 is carcinogenic to the lungs of male and female F344 rats, however no plural mesothelioma was observed.

Keywords: Lung carcinoma, Lung carcinogenicity, Multi-walled carbon nanotube, MWCNT, MWNT-7, Inhalation carcinogenicity, Whole body inhalation, Rat

\section{Background}

One of the most important developments in industrial technology is nanotechnology. Various nanomaterials, especially carbon nanotubes (CNTs), have exceptional electrical, mechanical, and thermal properties, enabling the commercialization of various types of CNTs for use with numerous applications in industry, and in recent years the production of CNTs has significantly increased [1]. On the other hand, with the rapid growth of CNT use, serious concerns have been expressed about their adverse effects on the health of workers during CNT manufacturing and handling processes and on the health of consumers exposed to commercial end products

\footnotetext{
* Correspondence: tatsuya-kasai@jbrc.johas.go.jp

Japan Bioassay Research Center, Japan Organization of Occupational Health and Safety, 2445 Hirasawa, Hadano, Kanagawa 257-0015, Japan
}

containing CNTs. At present, however, neither epidemiological nor medical case studies have been reported on health consequences in CNT-exposed workers or consumers.

Long, straight types of multi-walled carbon nanotube (MWCNT) fibers, like asbestos, have a high aspect ratio and are able to persist in biological tissues $[2,3]$. The "Stanton hypothesis" [4,5], also known as the fiber paradigm [6], asserts that fibers longer than $8 \mu \mathrm{m}$ and less than $0.25 \mu \mathrm{m}$ in diameter have high carcinogenic potential. High aspect ratio fibers (especially fibers having diameters less than $3 \mu \mathrm{m}$ and lengths of greater than $5 \mu \mathrm{m}, \mathrm{L} / \mathrm{D}$ ratio $>3$ ) are thought to play an essential role in the induction of intrathoracic tumors by fibrous materials [2, 6-9]. Poland et al. reported that intraperitoneal administration in rodents of long, straight types of asbestos or MWCNT fibers, but not nanoparticulate 
carbon black or short asbestos fibers or short or tangled MWCNT, resulted in asbestos-like pathogenic responses [10]. Thus, there is obvious reason for concern for possible asbestos-like health effects, such as induction of pulmonary carcinoma and mesothelioma, by exposure to fibrous MWCNTs. Importantly, Takagi et al. [11] demonstrated that peritoneal mesotheliomas were induced by intraperitoneal administration of one type of fibrous MWCNT (MITSUI MWCNT-7, MWNT-7 in the present study) to p53 knockout mice. Subsequently, several studies reported that malignant mesotheliomas developed in mice or rats after intraperitoneal or intrascrotal administration of MWNT-7 [2, 12-14]. Thus, MWNT-7 is carcinogenic to the mesothelium upon direct exposure.

MWCNT fibers are very light and easily become airborne, making inhalation the primary route of human exposure $[15,16]$. To assess the risk of MWCNT to exposed workers, in vivo toxicity studies in rodents exposed to MWCNT via inhalation are crucial. Ryman-Rasmussen et al. [17] and Porter et al. [18] reported that MWCNT inhaled by mice is toxic to lung and plural tissues, and Sargent et al. [19] reported that inhalation of MWCNT at $5 \mathrm{mg} / \mathrm{m}^{3}$ for 15 days followed by a 17 month postexposure period promoted methylcholanthrene initiated lungcarcinogenesis in mice. Taken together, these results show that airborne long straight MWCNT fibers are potentially carcinogenic to mouse lung and pleural tissues.

We have developed a dry aerosol generation and exposure system (cyclone sieve method) for whole-body inhalation exposure to MWCNTs. Using this method, we conducted 6-h, 2-week, and 13-week inhalation studies of MWNT-7 using rats [20-22]. The results revealed persistent inflammation and granulomatous changes with multinucleated giant cells in the lung, a concentration-dependent increase in the deposition of MWNT-7 in the lung, and the presence of MWCNTcontaining alveolar macrophages. The concentrationdependent increase in the retention of MWNT-7 in the lung was associated with the severity of toxicity and was particularly apparent in the 13-week study [22]. Importantly, MWNT-7 fibers were also observed in the subpleural area and diaphragm. These results indicate that inhaled MWNT-7 is deposited deep into the respiratory tract and can be translocated into the pleural cavity, and that exposure to MWNT-7 induces pathological changes in the lung and chest cavity.

Taken together, the results of all of the studies cited above led to the hypothesis that inhalation of MWNT-7 aerosol may result in tumor development in the lung and possibly the pleura. Therefore, in order to clarify the carcinogenicity of MWNT-7, we conducted a 2-year carcinogenicity study of MWNT-7 by whole body inhalation based on a widely accepted protocol [23]. In this study, F344 male and female rats, 6-weeks-old at the commencement of the study, were exposed to MWNT-7 aerosol for $6 \mathrm{~h} /$ day, 5 days/week for 104 weeks at concentrations of $0,0.02,0.2$, and $2 \mathrm{mg} / \mathrm{m}^{3}$ using our dry aerosol generation and exposure system.

\section{Results \\ Environmental conditions of the inhalation chambers}

All inhalation chambers were maintained at an air exchange rate of 10 times/h $(1668-1671 \mathrm{l} / \mathrm{min})$, a temperature of $22.9-23.0{ }^{\circ} \mathrm{C}$, and a humidity of $52.7-$ $53.8 \%$ during each exposure period (Table 1 ).

\section{MWNT-7 concentrations and particle size distributions}

MWNT-7 aerosols were freshly generated during each exposure period, and the MWNT-7 concentrations in the inhalation chambers were at the target doses throughout the 104-week experimental period: $0.020 \pm 0.001$ (mean \pm SD) $\mathrm{mg} / \mathrm{m}^{3}$ for the $0.02 \mathrm{mg} / \mathrm{m}^{3}$ group, $0.204 \pm 0.014 \mathrm{mg} /$ $\mathrm{m}^{3}$ for the $0.2 \mathrm{mg} / \mathrm{m}^{3}$ group, and $2.018 \pm 0.069 \mathrm{mg} / \mathrm{m}^{3}$ for the $2 \mathrm{mg} / \mathrm{m}^{3}$ group. Figure 1a shows the concentrations of the MWNT-7 aerosols in the inhalation chambers throughout the experimental period. Mass median aerodynamic diameters (MMAD) and geometric standard deviations (GSD) of the MWNT-7 aerosol were in the range of 1.2-1.4 $\mu \mathrm{m}$ and 2.6-3.0 in all MWNT-7-exposed groups (Table 1). Scanning electron microscope (SEM) of MWNT-7 collected on polycarbonate filters demonstrated that most MWNT-7 s were single straight fibers and were not aggregated, and no differences in MWNT-7 shape were found between the three target concentrations in any of the samples collected. Typical images of samples collected on weeks 1 and 102 are shown in Fig. 1b and c.

\section{Clinical observations, urinary, hematological and blood biochemical analyses}

Neither MWNT-7- related deaths nor clinical signs were observed in any MWNT-7-exposed male or female animals during the 104-week experimental period. Survival rates and body weight curves of male and female rats from the MWNT-7 and control groups are shown in Fig. 2. There were no differences between control and exposure group survival rates of either male or female rats; the survival rates exceeded $72 \%$ and $68 \%$ at the end of 104-week experimental period for males and females, respectively (Table 2 ). No growth retardation was found in any of the male or female groups during the experiment. The relative body weights of the 0.02 , 0.2 , and $2 \mathrm{mg} / \mathrm{m}^{3}$-exposed animals at the end of experiment were 98,102 , and $100 \%$ for males and 95 , 100 , and $94 \%$ for females, respectively, compared to their respective controls (Table 2).

Urinary, hematological, and blood biochemical analyses revealed no toxicological changes in either male or female 
Table 1 Characterization of chamber environment

\begin{tabular}{|c|c|c|c|c|}
\hline Target concentration $\left(\mathrm{mg} / \mathrm{m}^{3}\right)$ & 0 & 0.02 & 0.2 & 2 \\
\hline Temperature $\left({ }^{\circ} \mathrm{C}\right)$ & $23.0 \pm 0.2$ & $22.9 \pm 0.1$ & $23.0 \pm 0.2$ & $23.0 \pm 0.2$ \\
\hline Humidity (\%) & $53.8 \pm 1.8$ & $52.9 \pm 2.4$ & $53.3 \pm 2.1$ & $52.7 \pm 2.0$ \\
\hline Chamber air flow (L/min) & $1670 \pm 37$ & $1671 \pm 36$ & $1671 \pm 37$ & $1668 \pm 38$ \\
\hline Mass concentration $\left(\mathrm{mg} / \mathrm{m}^{3}\right)^{a}$ & $0.000 \pm 0.000$ & $0.020 \pm 0.001$ & $0.204 \pm 0.014$ & $2.018 \pm 0.069$ \\
\hline MMAD (GSD): 1 week $^{\text {b }}$ & - & $1.3 \mu \mathrm{m}(3.0)$ & $1.4 \mu \mathrm{m}(2.9)$ & $1.3 \mu \mathrm{m}(2.6)$ \\
\hline MMAD (GSD): 14 week & - & $1.3 \mu \mathrm{m}(2.8)$ & $1.3 \mu \mathrm{m}(2.9)$ & $1.3 \mu \mathrm{m}(2.9)$ \\
\hline MMAD (GSD): 27 week & - & $1.3 \mu \mathrm{m}(2.9)$ & $1.3 \mu \mathrm{m}(2.9)$ & $1.3 \mu \mathrm{m}(2.8)$ \\
\hline MMAD (GSD): 40 week & - & $1.3 \mu \mathrm{m}(2.9)$ & $1.3 \mu \mathrm{m}(2.9)$ & $1.3 \mu \mathrm{m}(2.9)$ \\
\hline MMAD (GSD): 53 week & - & $1.4 \mu \mathrm{m}(3.0)$ & $1.4 \mu \mathrm{m}(2.9)$ & $1.4 \mu \mathrm{m}(2.9)$ \\
\hline MMAD (GSD): 66 week & - & $1.2 \mu \mathrm{m}(2.9)$ & $1.3 \mu \mathrm{m}(2.9)$ & $1.4 \mu \mathrm{m}(2.8)$ \\
\hline MMAD (GSD): 79 week & - & $1.3 \mu \mathrm{m}(2.9)$ & $1.3 \mu \mathrm{m}(2.9)$ & $1.4 \mu \mathrm{m}(2.8)$ \\
\hline MMAD (GSD): 92 week & - & $1.3 \mu \mathrm{m}(3.0)$ & $1.3 \mu \mathrm{m}(3.0)$ & $1.4 \mu \mathrm{m}(2.8)$ \\
\hline MMAD (GSD): 102 week & - & $1.4 \mu \mathrm{m}(2.9)$ & $1.3 \mu \mathrm{m}(2.7)$ & $1.3 \mu \mathrm{m}(2.9)$ \\
\hline
\end{tabular}

Values indicates means \pm SD

${ }^{a}$ The mass concentrations were calibrated from the particle concentration of MWNT-7 in the inhalation chamber measured by the OPC

${ }^{b}$ MMAD: Mass median aerodynamic diameter, GSD: geometric standard deviation

rats exposed to $0.02,0.2$, or $2 \mathrm{mg} / \mathrm{m}^{3}$ compared with their respective controls (data not shown).

\section{Macroscopic findings and organ weights}

At the terminal necropsy, multiple grayish, white areas and nodules were found in the lungs of a large number of male and female rats exposed to $2 \mathrm{mg} / \mathrm{m}^{3}$ MWNT-7. The color tone of the lung surface was darkened in line with the exposure concentration (Fig. 3a and b). There were no MWNT-7-specific macroscopic findings in the other organs, including the pleura and peritoneum of the animals that survived to the end of the experiment or the animals that died or were sacrificed before the end of the experiment.

Absolute and relative lung weights were significantly elevated in male rats exposed to 0.2 and $2 \mathrm{mg} / \mathrm{m}^{3}$ MWNT-7, and they were significantly increased in all exposed female groups (Table 2). No MWNT-7 exposurerelated increases were found in the other organs.

\section{Microscopic findings}

The results of histopathological examination of the lungs, peritoneum and pleura are shown in Table 3. The incidences of bronchiolo-alveolar carcinomas, total carcinomas (bronchiolo-alveolar carcinomas, adenosquamous carcinoma, adenocarcinoma and squamous cell carcinoma), and total carcinomas and/or adenomas in males exposed to 0.2 and $2 \mathrm{mg} / \mathrm{m}^{3} \mathrm{MWNT}-7$ and females exposed to $2 \mathrm{mg} / \mathrm{m}^{3} \mathrm{MWNT}-7$ were significantly increased compared with their respective control groups. One adenosquamous carcinoma was found in each of the $2 \mathrm{mg} / \mathrm{m}^{3}$-exposed male and female groups, and one poorly differentiated adenocarcinoma and one squamous cell carcinoma were found in the $2 \mathrm{mg} / \mathrm{m}^{3}$ exposed female group; these malignant tumors very rarely arise spontaneously: no such tumors were observed in 599 control males or 600 control females in previous 104-week inhalation carcinogenicity studies in rats conducted by our institute during the last 10 years. Most bronchiolo-alveolar tumors were single tumors, while adenosquamous carcinoma, poorly differentiated adenocarcinoma, and squamous cell carcinoma tended to be multiple tumors. Tumor cells of the bronchioloalveolar tumors destroyed the alveolar structure and invaded the walls of bronchioles and blood vessels (Fig. 3c). It was noteworthy that the MWNT-7-induced bronchiolo-alveolar carcinomas were often accompanied by proliferative fibrous connective tissue, which was not present in the spontaneous lung carcinoma that developed in the control male rat (Fig. 3d).

No MWNT-7-related tumors were induced in the other organs including the pleural and peritoneal mesothelium.

Incidences of bronchiolo-alveolar hyperplasia and alveolar hyperplasia were significantly increased in male rats exposed to 0.2 and $2 \mathrm{mg} / \mathrm{m}^{3}$ MWNT-7 and in female rats exposed to $2 \mathrm{mg} / \mathrm{m}^{3}$ MWNT-7. Incidences of bronchiolar hyperplasia and atypical hyperplasia were significantly increased in male and female rats exposed to $2 \mathrm{mg} / \mathrm{m}^{3} \mathrm{MWNT}-7$. Atypical hyperplasia consisted of epithelial cells with atypia and was accompanied by development of proliferative fibrous connective tissue and alveolar macrophages with phagocytosed MWNT-7 (Fig. 3e). Alveolar hyperplasia was composed of localized proliferation of type II alveolar epithelial cells, 


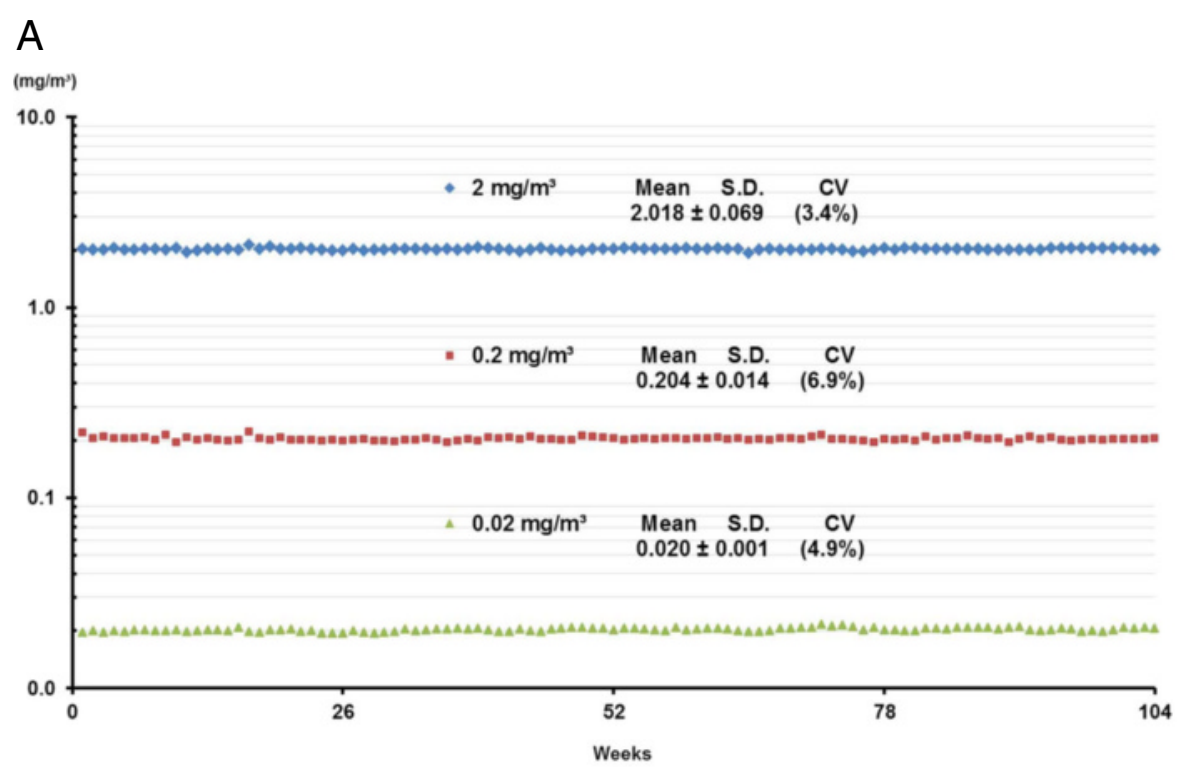

B

Administration 1 week
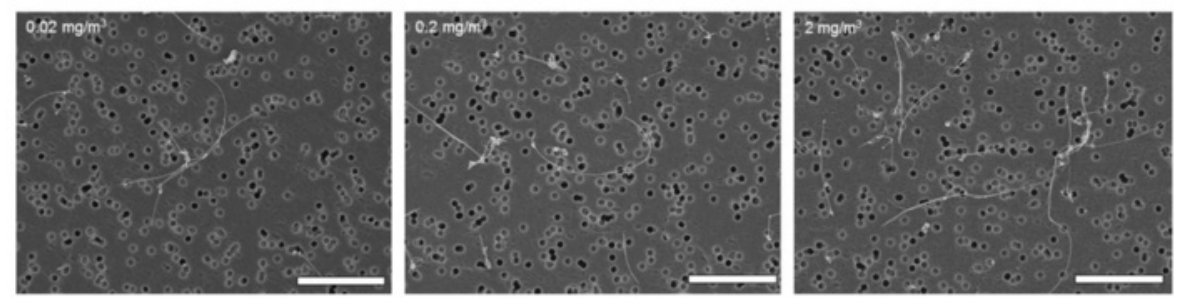

C

Administration 102 weeks
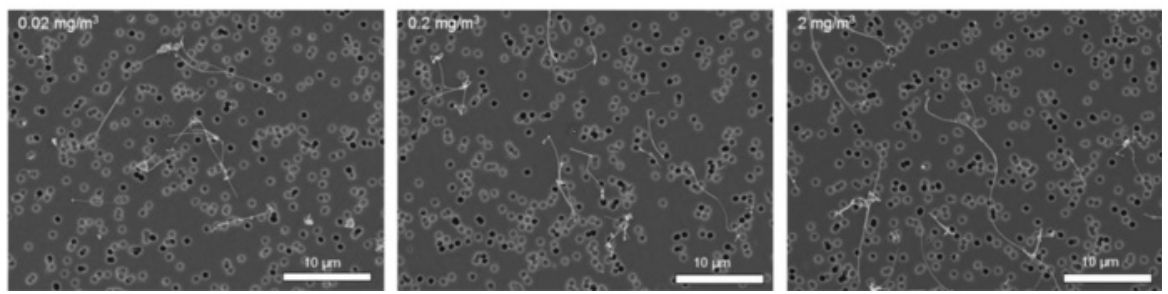

Fig. 1 a MWNT-7 concentrations in the inhalation chambers during the 104-week experimental period. Concentrations of MWNT-7 particles in the inhalation chamber were monitored by the optical particle controller throughout each $6 \mathrm{~h}$ exposure period during the 104 weeks of the study. Mass concentrations $\left(\mathrm{mg} / \mathrm{m}^{3}\right)$ of MWNT-7 in the chambers was calibrated by multiplying the CPM by the mass per particle (see Methods for details). The target concentrations of MWNT-7 were $0.02,0.2$, and $2 \mathrm{mg} / \mathrm{m}^{3}$; panel A shows the measured concentrations of MWNT-7 aerosols in the chambers. $\mathbf{b}$ and $\mathbf{c}$ SEM images of MWNT-7 in the inhalation chamber. SEM images of MWNT-7 in the chamber are shown in panels $\mathbf{b}$ and c. The fibers shown in the figure were collected on a polycarbonate filter at 1-week and 102 weeks. The MWNT-7 aerosol was in the form of individual and fibers in all groups. Bar, 5 mm

accompanied by fractured alveolar macrophages in the alveolar space. Bronchiolar hyperplasia was composed mainly of proliferating ciliated columnar epithelial cells in the terminal bronchiole area. Significantly elevated incidences of granulomatous change and focal fibrosis of the alveolar wall were noted in male and female rats exposed to 0.2 and $2 \mathrm{mg} / \mathrm{m}^{3}$ MWNT-7. Focal fibrosis, characterized by thickening and increased collagen fibers, was often associated with the granulomatous changes. Alveolar macrophages, with phagocytosed MWNT-7 s accumulated in the alveolar spaces in male and female rats exposed to $2 \mathrm{mg} / \mathrm{m}^{3}$ MWNT-7.

In the pleura, incidences of simple mesothelial hyperplasia of the parietal pleura (Fig. 3f) and focal fibrosis of the parietal pleura side of the diaphragm were increased in male rats exposed to $2 \mathrm{mg} / \mathrm{m}^{3}$ MWNT-7. 


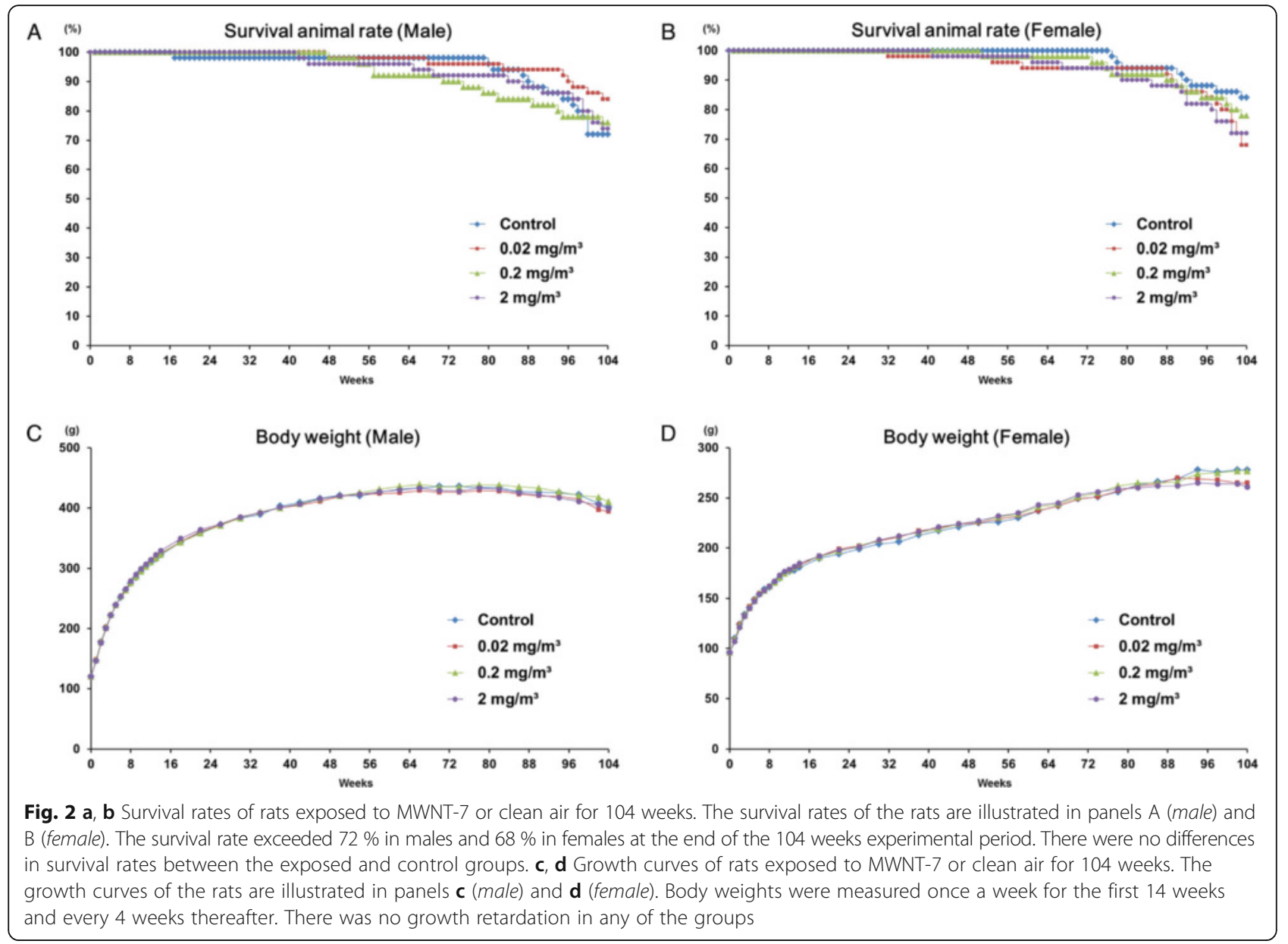

Table 2 Absolute and relative, body weights and lung weights in rats exposed to MWNT-7 for 104 weeks

\begin{tabular}{|c|c|c|c|c|c|c|c|c|}
\hline \multirow[b]{2}{*}{ Group $\left(\mathrm{mg} / \mathrm{m}^{3}\right)$} & \multicolumn{4}{|l|}{ Male } & \multicolumn{4}{|c|}{ Female } \\
\hline & 0 & 0.02 & 0.2 & 2 & 0 & 0.02 & 0.2 & 2 \\
\hline Numbers of animals examined & 50 & 50 & 50 & 50 & 50 & 50 & 50 & 50 \\
\hline Survival animal number & 36 & 42 & 38 & 37 & 42 & 34 & 39 & 36 \\
\hline (rate:\%) & $(72)$ & $(84)$ & (76) & (74) & $(84)$ & (68) & (78) & $(72)$ \\
\hline \multicolumn{9}{|l|}{ Body weight } \\
\hline Terminal body weight $(\mathrm{g})$ mean & 401 & 394 & 410 & 399 & 278 & 265 & 277 & $261 *$ \\
\hline SD & 45 & 37 & 39 & 38 & 31 & 26 & 23 & 26 \\
\hline Relative body weight (\%) mean & 100 & 98 & 102 & 100 & 100 & 95 & 100 & 94 \\
\hline \multicolumn{9}{|l|}{ Lung weight } \\
\hline Terminal lung weight (g) mean & 1.31 & 1.34 & $1.51^{* *}$ & $2.37^{* *}$ & 0.90 & $0.94^{* *}$ & $1.14 * *$ & $1.87^{* *}$ \\
\hline SD & 0.10 & 0.12 & 0.13 & 0.31 & 0.21 & 0.10 & 0.27 & 0.18 \\
\hline Relative lung weight (\%) mean & 0.36 & 0.37 & $0.40^{* *}$ & $0.65^{* *}$ & 0.35 & $0.38^{* *}$ & $0.45 * *$ & $0.79 * *$ \\
\hline SD & 0.06 & 0.05 & 0.06 & 0.20 & 0.10 & 0.05 & 0.14 & 0.16 \\
\hline
\end{tabular}

Terminal body weight (g): Absolute body weight at the end of 104 weeks

Relative body weight (\%): Percentage of the body weight in the control group

Terminal lung weight (g): Absolute lung weight at the end of 104 weeks

Relative lung weight (\%): Percentage of the terminal lung weight in each animal's body weight

Significant difference; *: $p \leqq 0.05 * *: p \leqq 0.01$ by Dunnett's Test 

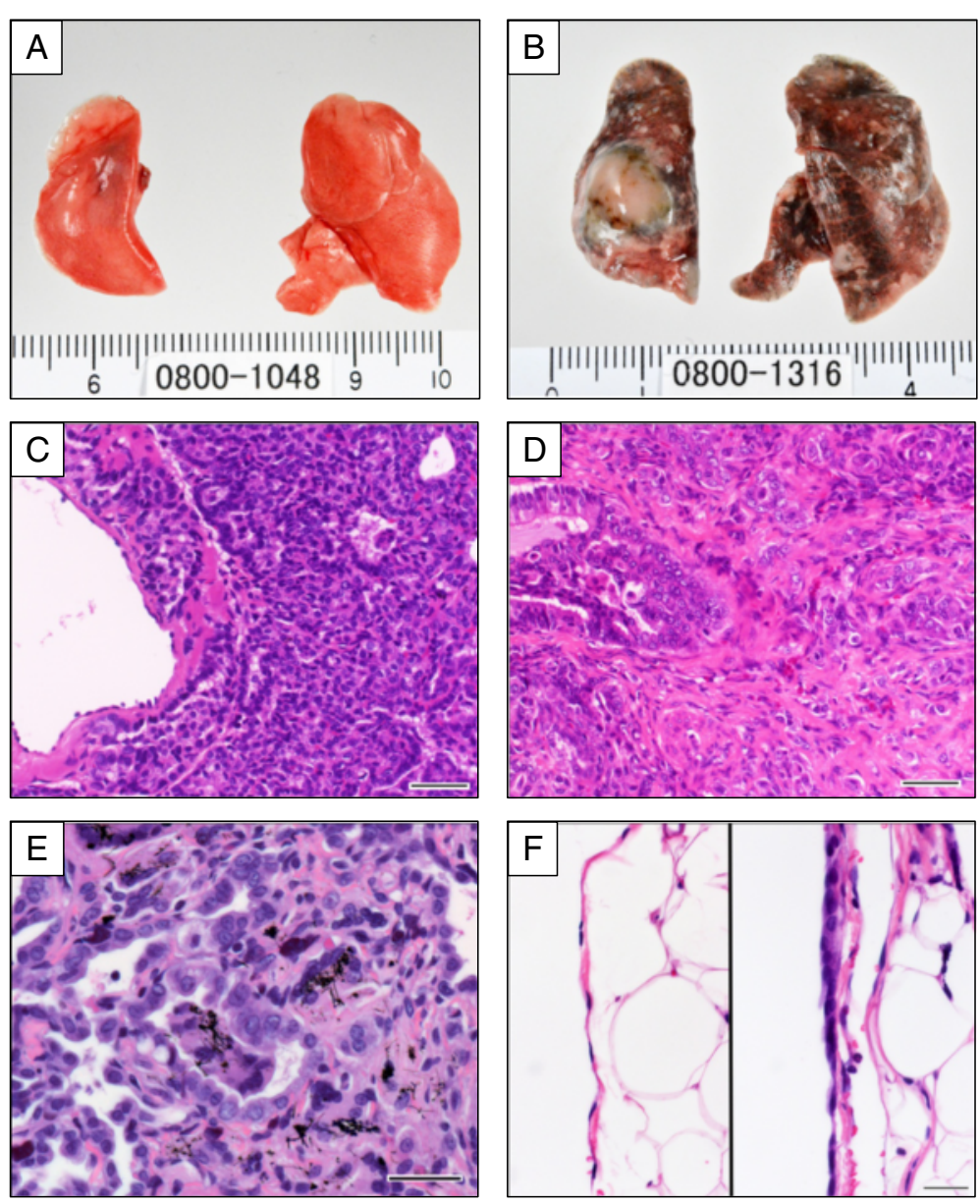

Fig. 3 Macroscopic and microscopic findings of the lungs and peritoneal pleura. a Lung from a control male rat. $\mathbf{b}$ Multiple white areas and nodules in the lungs of a $2 \mathrm{mg} / \mathrm{m}^{3}$ MWNT-7-exposed male. c Bronchiolo-alveolar carcinoma in the lung of the male rat exposed to $2 \mathrm{mg} / \mathrm{m}^{3}$ MWNT-7. Carcinoma cells invaded the wall of the vein. Bar, $50 \mu \mathrm{m}$. d Bronchiolo-alveolar carcinoma in the lung of a female rat exposed to $2 \mathrm{mg} /$ $\mathrm{m}^{3}$ MWNT-7. Proliferation of carcinoma cells accompanied by fibrous connective tissue is causing the disappearance of the existing alveolar construction. Bar, $50 \mu \mathrm{m}$. e Atypical hyperplasia accompanied by proliferative fibrous connective tissue and MWNT-7 deposition in the lung of a female rat exposed to $2 \mathrm{mg} / \mathrm{m}^{3}$ MWNT-7. Epithelial cell polarity is poorly defined and the nuclei of the cells vary in size. Bar, $30 \mu \mathrm{m}$. $\mathbf{f}$ The left image shows the normal parietal pleura of a control male rat. The right image shows a simple mesothelial hyperplasia of the parietal pleura in a male rat exposed to $2 \mathrm{mg} / \mathrm{m}^{3}$ MWNT-7. Bar, $25 \mu \mathrm{m}$

In female rats exposed to $2 \mathrm{mg} / \mathrm{m}^{3}$ MWNT-7, there was a non-significant increase in the incidences of simple mesothelial hyperplasia and focal fibrosis of the parietal pleura. The incidence of focal fibrosis of the ventral pleura was elevated in male and female rats exposed to $2 \mathrm{mg} / \mathrm{m}^{3}$ MWNT-7. Finally, the incidence of inflammation of the mediastinum was elevated in male rats exposed to $2 \mathrm{mg} / \mathrm{m}^{3}$ MWNT-7.

Goblet cell hyperplasia was also observed in the frontal respiratory epithelium of the nasal cavity and nasopharynx of male and female rats exposed to 0.2 and $2 \mathrm{mg} / \mathrm{m}^{3}$ MWNT-7 and in the respiratory epithelium of the nasopharynx of female rats exposed to $0.02 \mathrm{mg} / \mathrm{m}^{3}$ MWNT7. Incidences of eosinophilic globules, which appeared in the cytoplasm of the respiratory and olfactory epithelia in the nasal cavity, were increased in male and female rats exposed to 0.2 and $2 \mathrm{mg} / \mathrm{m}^{3}$ MWNT-7. Eosinophilic globules could be the normal reaction to mild irritation [24]. No remarkable non-neoplastic changes were found in the other organs.

Microscopically, single or aggregated MWNT-7 s were found in the nasal cavity, larynx, trachea, lungs, lymph nodes, spleen, liver, kidneys, olfactory bulb, and brain of the exposed rats of both sexes. MWNT-7 fibers in the kidney, olfactory bulb, and brain were single and not aggregated. The degree of MWNT-7 deposition in the lungs and mediastinal lymph nodes was concentration-dependent. Little MWNT-7 was 
Table 3 Histopathological findings of the lung, peritoneum and pleura in rats exposed to MWNT-7 for 104 weeks

\begin{tabular}{|c|c|c|c|c|c|c|c|c|c|c|}
\hline \multirow[b]{2}{*}{ Group $\left(\mathrm{mg} / \mathrm{m}^{3}\right)$} & \multicolumn{4}{|l|}{ Male } & \multirow[t]{2}{*}{ Peto test } & \multicolumn{4}{|l|}{ Female } & \multirow[t]{3}{*}{ Peto test } \\
\hline & $\overline{0}$ & 0.02 & 0.2 & 2 & & $\overline{0}$ & 0.02 & 0.2 & 2 & \\
\hline Number of animals examined & 50 & 50 & 50 & 50 & & 50 & 50 & 50 & 50 & \\
\hline \multicolumn{11}{|l|}{ Neoplastic lesions } \\
\hline \multicolumn{11}{|l|}{ Lung } \\
\hline Bronchiolo-alveolar carcinoma & 1 & 1 & $8^{\#}$ & $10^{\# \#}$ & $\uparrow \uparrow$ & 0 & 1 & 0 & $5^{\# \#}$ & $\uparrow \uparrow$ \\
\hline Adenosquamous carcinoma & 0 & 0 & 0 & 1 & & 0 & 0 & 0 & 1 & \\
\hline Poorly differentiated adenocarcinoma & 0 & 0 & 0 & 0 & & 0 & 0 & 0 & 1 & \\
\hline Squamous carcinoma & 0 & 0 & 0 & 0 & & 0 & 0 & 0 & 1 & \\
\hline Total carcinoma & 1 & 1 & $8^{\#}$ & $11^{\# \#}$ & $\uparrow \uparrow$ & 0 & 1 & 0 & $8^{\# \#}$ & $\uparrow \uparrow$ \\
\hline Bronchiolo-alveolar adenoma & 1 & 1 & $7^{\#}$ & 5 & & 3 & 1 & 4 & 3 & \\
\hline Total adenoma and/or carcinoma & 2 & 2 & $13^{\# \#}$ & $16^{\# \#}$ & $\uparrow \uparrow$ & 3 & 2 & 4 & $11^{\#}$ & $\uparrow \uparrow$ \\
\hline \multicolumn{11}{|l|}{ Peritoneum } \\
\hline Malignant mesothelioma & 0 & 3 & 1 & 1 & & 0 & 0 & 0 & 0 & \\
\hline \multicolumn{11}{|l|}{ Non-neoplastic lesions } \\
\hline \multicolumn{11}{|l|}{ Lung } \\
\hline Bronchiolo-alveolar hyperplasia & $2(1.5)$ & $6(1.3)$ & $13 *(1.2)$ & $22 * *(1.0)$ & & $3(1.3)$ & $3(1.0)$ & $8(1.1)$ & $12 *(1.1)$ & \\
\hline Atypical hyperplasia & 0 & 0 & $1(1.0)$ & $10 * *(1.3)$ & & 0 & 0 & 0 & $14^{* *}(1.1)$ & \\
\hline Alveolar hyperplasia & 0 & $2(1.0)$ & $13 * *(1.0)$ & $41 * *(1.0)$ & & $1(1.0)$ & $1(1.0)$ & $6(1.0)$ & $41 * *(1.1)$ & \\
\hline Bronchiolar hyperplasia & 0 & 0 & $4(1.0)$ & $8 * *(1.0)$ & & $0(1.0)$ & $0(1.0)$ & $4(1.0)$ & $26 * *(1.0)$ & \\
\hline Accumulation: alveolar macrophage & $2(1.0)$ & $7(1.0)$ & $5(1.0)$ & $48^{* *}(2.0)$ & & $2(1.0)$ & $6(1.0)$ & $9(1.0)$ & $48 * *(1.8)$ & \\
\hline Focal fibrosis: alveolar wall & 0 & $2(1.0)$ & $43 * *(1.0)$ & $48 * *(1.8)$ & & 0 & $3(1.0)$ & $44 * *(1.0)$ & $49 * *(1.2)$ & \\
\hline Granulomatous change & 0 & $5(1.0)$ & $42 * *(1.0)$ & $50 * *(1.9)$ & & 0 & $3(1.0)$ & $45^{* *}(1.0)$ & $50 * *(1.8)$ & \\
\hline \multicolumn{11}{|l|}{ Pleura } \\
\hline Simple mesothelial hyperplasia & $3(1.0)$ & $3(1.0)$ & $7(1.0)$ & $12 *(1.0)$ & & $3(1.0)$ & $2(1.0)$ & $6(1.0)$ & $10(1.0)$ & \\
\hline Focal fibrosis: parietal (diaphragm) & 0 & 0 & $2(1.0)$ & $6 *(1.0)$ & & 0 & 0 & 0 & $3(1.0)$ & \\
\hline Focal fibrosis: ventral (lung) & $0(1.0)$ & $2(1.0)$ & $4(1.0)$ & $19 * *(1.1)$ & & 0 & $2(1.0)$ & $2(1.0)$ & $20 * *(1.0)$ & \\
\hline Inflammation: mediastinum & $15(1.0)$ & $18(1.0)$ & $21(1.0)$ & $26 *(1.0)$ & & $17(1.0)$ & $17(1.0)$ & $16(1.0)$ & $19(1.0)$ & \\
\hline Inflammation: diaphragm & 0 & 0 & $1(1.0)$ & $1(1.0)$ & & 0 & $1(1.0)$ & $1(1.0)$ & $1(1.0)$ & \\
\hline
\end{tabular}

Values indicate number of animals bearing the lesion

Values in parentheses are the average of severity grade indexes of the lesions in affected animals. The average of severity grade indexes are calculated with a following equation. ( $\Sigma($ grade $\times$ number of animals with grade) ) $\div$ number of affected animals. Grade: $1=$ slight, $2=$ moderate, $3=$ marked, $4=$ severe Significant difference; ${ }^{*}: p \leq 0.05,{ }^{* *}: p \leq 0.01$ by Chi-square Test, \#: $p \leq 0.05, \# \#: p \leq 0.01$ by Fisher Exact Test, $\uparrow: p \leq 0.05, \uparrow \uparrow: p \leq 0.01$ by Peto's Test

observed by light microscopy outside of the lungs and mediastinal lymph nodes.

\section{Cytological and biochemical analyses of bronchoalveolar lavage fluid (BALF)}

The numbers of neutrophils, eosinophils, lymphocytes, and macrophages were increased in the BALF of males and females concentration-dependently and neutrophils, eosinophils, and lymphocytes were significantly elevated in $2 \mathrm{mg} / \mathrm{m}^{3}$ MWNT-7 exposed males and females, and macrophages were also significantly higher in $2 \mathrm{mg} / \mathrm{m}^{3}$ MWNT-7 exposed females (Fig. 4a). ALP, LDH, and total protein levels were also elevated in the BALF of males and females concentration-dependently and were significantly elevated in males and females exposed to 0.2 and $2 \mathrm{mg} / \mathrm{m}^{3}$ MWNT-7 (Fig. $4 \mathrm{~b}$ ).

\section{MWNT-7 lung burden}

Figure 5 shows the MWNT-7 lung burden of the rats that were euthanized or died before the end of the 104week experimental period. The amount of retained MWNT-7 was related to the MWNT-7 concentration and overall exposure time. The results of the lung burden analysis of MWNT-7 at the end of exposure period are presented in Fig. 6. Amounts of MWNT-7 in the lungs increased linearly with concentration in both males and females (Fig. 6a). The relative amounts of MWNT-7 per body weight were similar between the 

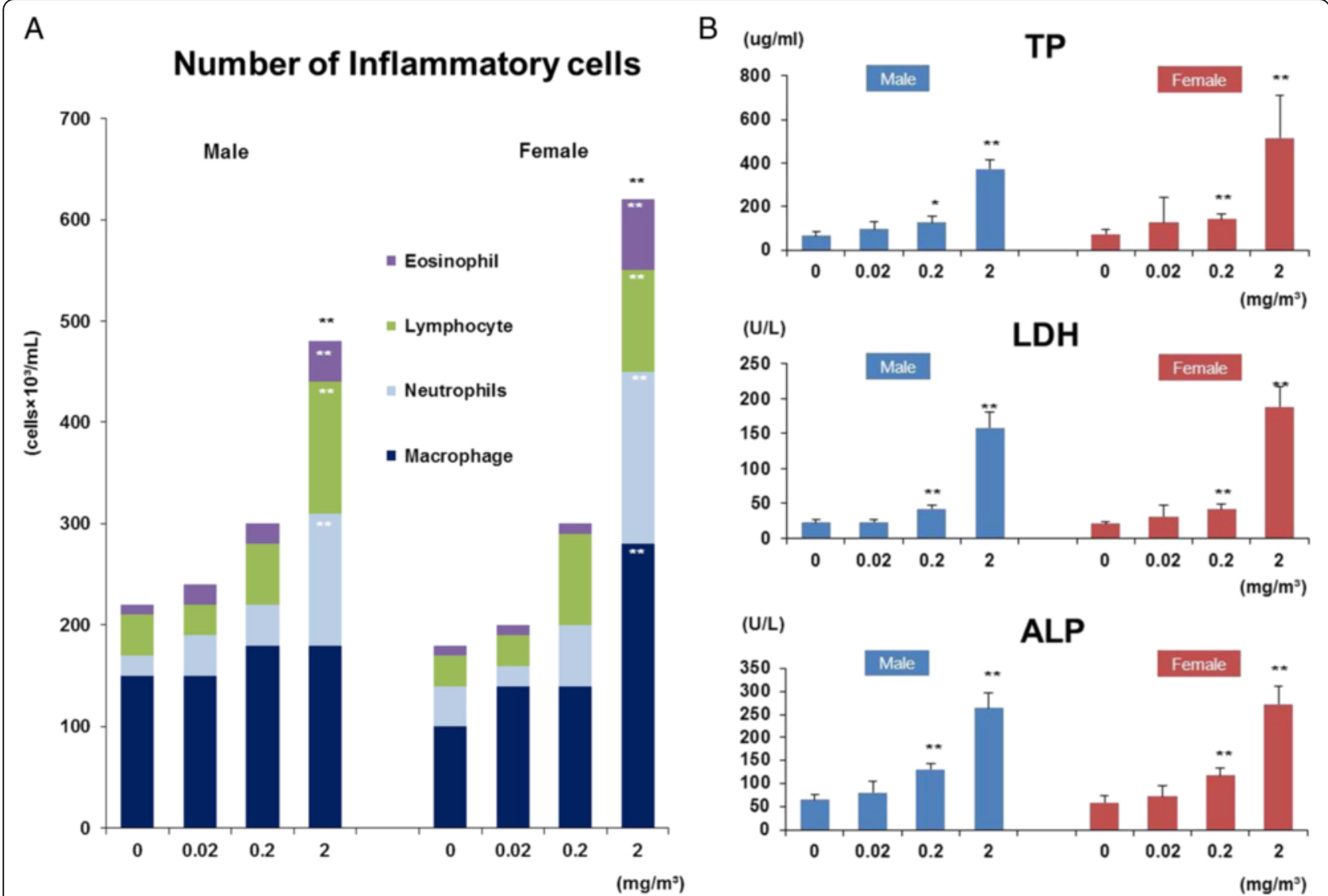

Fig. 4 Cytological and biochemical analyses of bronchoalveolar lavage fluid (BALF). a Cytological analyses. Total cells per $1 \mathrm{ml}$ in the BALF is shown. There is a concentration-dependent increase in the numbers of inflammatory cells, and the numbers of eosinophils, lymphocytes, neutrophils, and macrophages in the males and females exposed to $2 \mathrm{mg} / \mathrm{m}^{3}$ MWNT-7 are significantly increased. ${ }^{* *}: p<0.01$ by Dunnett's multiple comparison test. b Biochemical analyses: Total protein (Tp), Lactate dehydrogenase (LDH), and alkaline phosphatase (ALP) levels in the BALF were determined for male and female rats. Error bars indicate the SD for 5 rats. Tp, LDH, and ALP are significantly increased in a concentration-dependent manner in males and females. *: $p<0.05$ and ${ }^{* *}: p<0.01$ by Dunnett's multiple comparison test

males and females in the different exposure groups (Fig. 6b).

A summary of the incidence of lung carcinoma and the lung burden of MWNT-7 in the exposed groups at the end of the 104-week experimental period is given in Table 4. One $\mu \mathrm{g}$ of MWNT-7 was determined to equal $9.03 \times 10^{6}$ MWNT-7 fibers by SEM examination. The numbers of MWNT-7 fibers in the lungs of each exposure group was calculated based on this number of MWNT-7 fibers per $\mu \mathrm{g}$ and the result of the lung burden analysis. The number of MWNT-7 fibers in the lung increased in a concentration dependent manner (Table 4). The number of fibers per body weight were similar between males and females in the different concentration groups. The number of fibers that induced lung carcinoma was calculated to be $1.38 \times 10^{9} \mathrm{MWNT}$ 7 fibers in $0.2 \mathrm{mg} / \mathrm{m}^{3}$ MWNT-7 exposed males and $10.4 \times 10^{9}$ MWNT-7 fibers in $2 \mathrm{mg} / \mathrm{m}^{3}$ MWNT-7 exposed females. The number of fibers per gram body weight that induced lung carcinoma was calculated to be
$3.92 \times 10^{6}$ MWNT-7 fibers/gram body weight in males and $42.5 \times 10^{6}$ MWNT-7 fibers/gram body weight in females.

\section{Observation of MWNT-7 in the lung}

To observe MWNT-7 in the lung, lung tissues were digested, and specimens were observed by SEM. Alveolar macrophages which were digested completely or incompletely were obtained from lung tissues. Figure $7 \mathrm{a}$ is an incompletely digested macrophage phagocytosing MWNT-7, while Fig. 7b shows a completely digested macrophage. Figure $7 \mathrm{~b}$ shows a cocoon-like mass approximately $12 \mu \mathrm{m}$ in diameter formed by MWNT-7 fibers. The fibers in these masses wound around each other to form a dense aggregate. The size of the MWNT-7 masses was approximately $10-20 \mu \mathrm{m}$ in diameter, and the number of the masses present in the lungs increased concentration-dependently (data not shown). These large aggregates of MWNT-7 fibers came from alveolar macrophages, because MWNT-7 


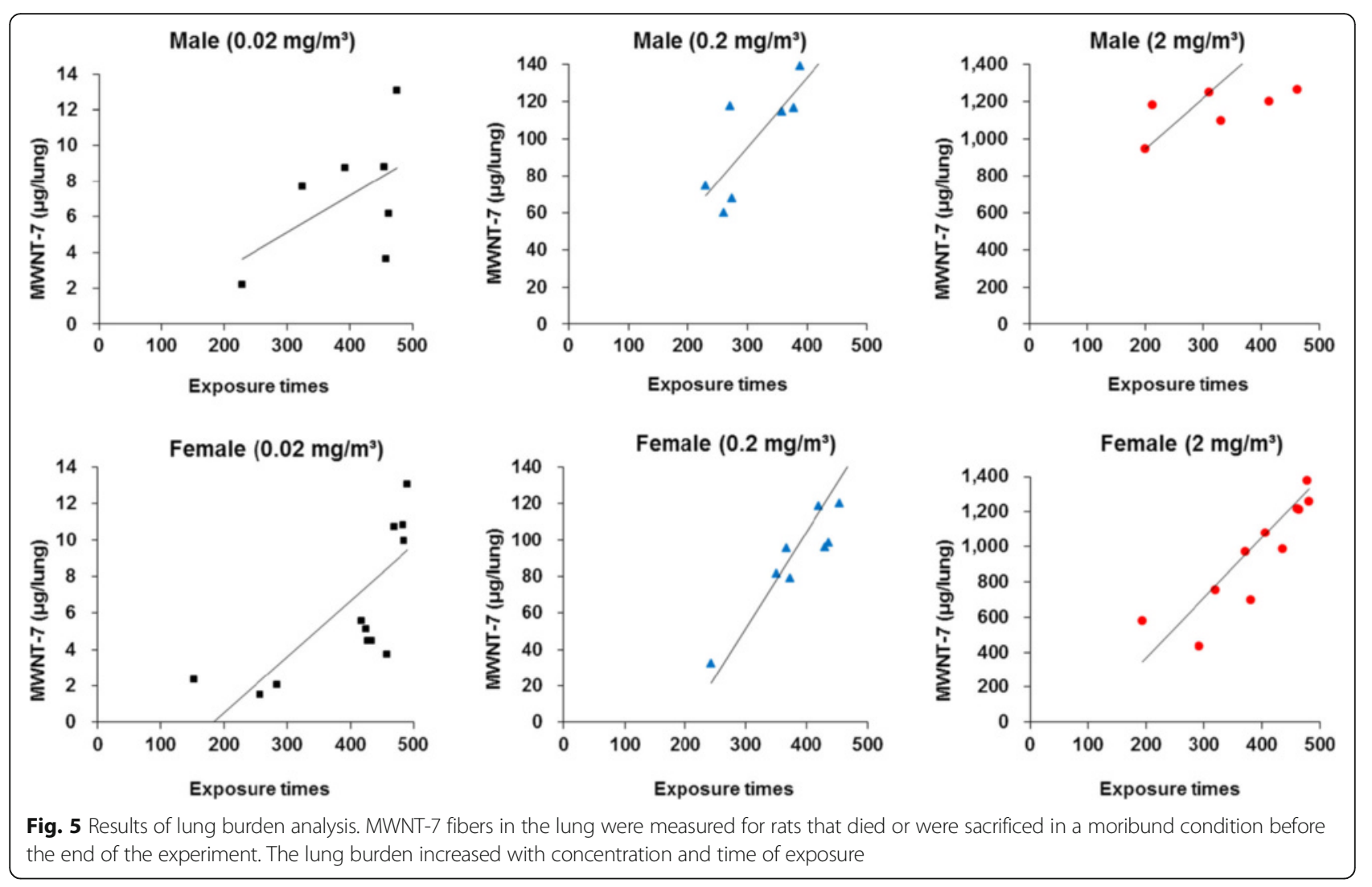

aggregates were also observed in incompletely digested alveolar macrophages. Importantly, these aggregates of MWNT-7 fibers were not observed in the MWNT-7 aerosols in any of the inhalation chambers.

\section{Measurement of the number MWNT-7 in pleural and ab- dominal lavage fluid}

MWNT-7 fibers were present in pleural and abdominal lavage fluid. The number of MWNT-7 fibers in the pleural area were 38,134 , and 1468 fibers in the 0.02 , 0.2 , and $2 \mathrm{mg} / \mathrm{m}^{3}$ exposed males and 23, 240, and 847 fibers in the $0.02,0.2$, and $2 \mathrm{mg} / \mathrm{m}^{3}$ exposed females. The number of MWNT-7 fibers in the abdominal area were 16,161 , and 2429 fibers in the $0.02,0.2$, and $2 \mathrm{mg} /$ $\mathrm{m}^{3}$ exposed males and 34, 294, and 3329 fibers in the $0.02,0.2$, and $2 \mathrm{mg} / \mathrm{m}^{3}$ exposed females. SEM examination revealed that in the pleural and the abdominal lavage fluid the MWNT-7 were individual, long, straight fibers and not aggregated (Fig. 7c and d).

\section{Discussion}

To test for potential hazard to humans of airborne straight, fibrous MWCNT, rats were exposed to MWNT7 aerosol for 6 h/day, 5 days/week for 104 weeks. Airborne MWNT-7 showed clear lung carcinogenicity.
Exposure to MWNT-7 aerosol for 104 weeks was found to cause statistically significant increases in the incidences of lung carcinomas and combined adenomas and carcinomas in males exposed to 0.2 and $2 \mathrm{mg} / \mathrm{m}^{3}$ MWNT-7 and in females exposed to $2 \mathrm{mg} / \mathrm{m}^{3}$ MWNT7. The increased incidence of lung carcinomas and combined adenomas and carcinomas in males was clearly does-dependent. In both males and females, the lung carcinomas were mainly bronchiolo-alveolar carcinomas. In addition to bronchiolo-alveolar carcinomas, adenosquamous carcinomas, a squamous cell carcinoma, and a poorly differentiated adenocarcinoma were found in 1 male and 3 female rats exposed to $2 \mathrm{mg} / \mathrm{m}^{3}$ MWNT-7; these carcinomas very seldom develop spontaneously and are thus likely to be linked to MWNT-7 exposure. In addition, pre-neoplastic lesions (bronchiolo-alveolar hyperplasia and atypical hyperplasia $[25,26])$ and reactive hyperplasia (alveolar hyperplasia and bronchial hyperplasia $[25,27])$ in the lungs of male and female rats were significantly increased in a concentration-dependent manner. These results are consistent with the development of lung carcinoma.

In the present study, there were no abnormal clinical signs, suppression of body weight gain or delay of growth rate, or decreased survival rate in the exposed groups. Therefore, the highest exposure concentration, $2 \mathrm{mg} / \mathrm{m}^{3}$ 


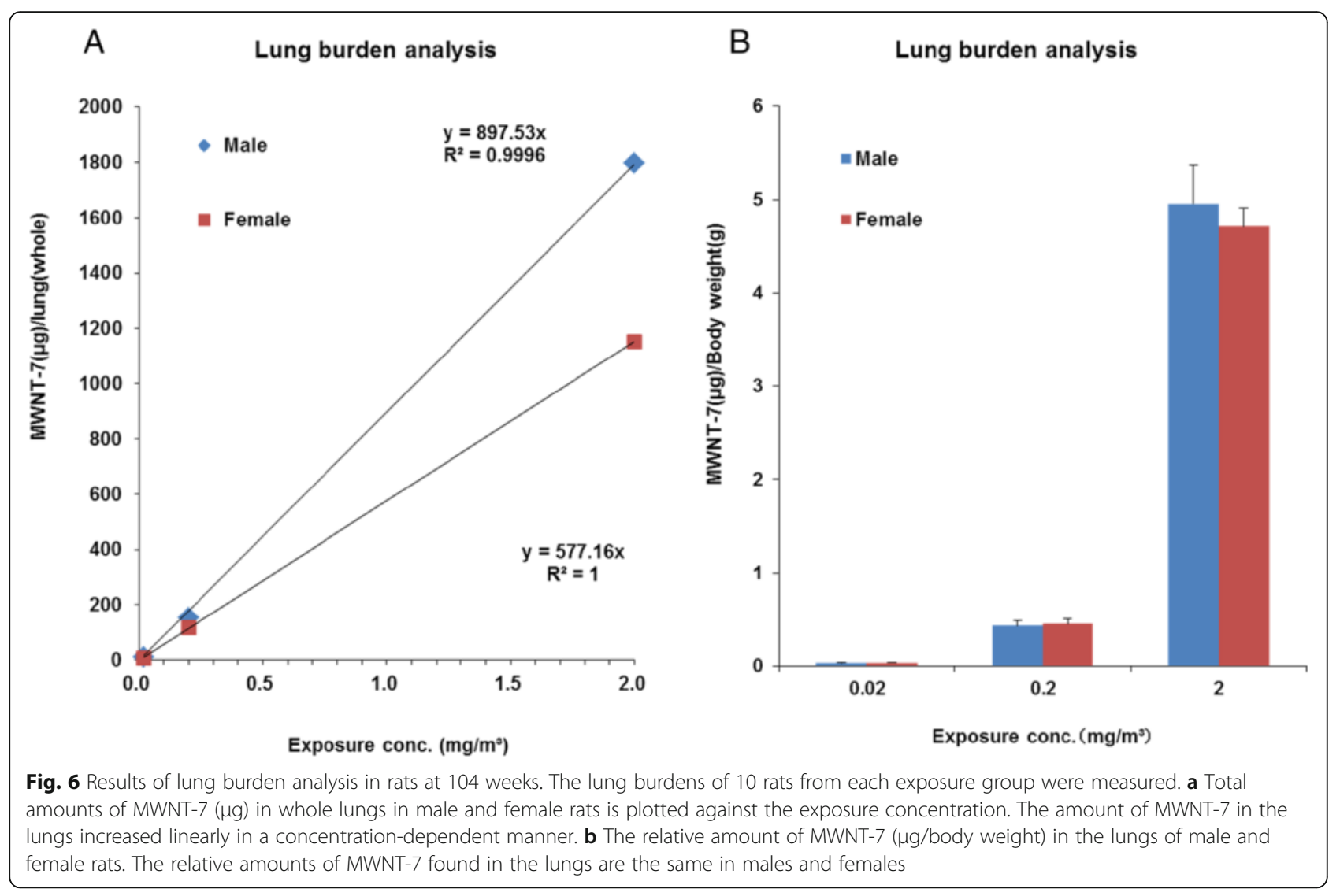

MWNT-7, fulfills the maximum tolerated dose (MTD) criteria $[28,29]$ for 104-week bioassay studies of rodent carcinogenicity: the highest dose of the carcinogenicity study should not alter the animals' normal longevity from toxic effects other than carcinogenicity, and there should be no more than a $10 \%$ weight decrement compared to the concurrent controls.
The fiber paradigm theorizes that longer fibers exert stronger toxic and carcinogenic effects than shorter ones because alveolar macrophages are unable to completely take up longer fibers [30]. In support of this theory, Muller et al. [31] reported that no mesotheliomas were observed in Wistar rats after intraperitoneal injection of MWCNT of average length less than $1 \mu \mathrm{m}$. Our results

Table 4 Incidence of lung carcinoma and lung burden in rats exposed to MWNT-7 for 104 weeks

\begin{tabular}{|c|c|c|c|c|c|}
\hline \multirow{2}{*}{$\begin{array}{l}\text { Concentration } \\
\left(\mathrm{mg} / \mathrm{m}^{3}\right)\end{array}$} & \multirow{2}{*}{$\begin{array}{l}\text { Lung carcinoma } \\
\text { incidence (\%) }\end{array}$} & \multirow[b]{2}{*}{$\begin{array}{l}\text { Amount of MWNT-7 } \\
\text { (ug/lung) }\end{array}$} & \multicolumn{2}{|l|}{ Lung burden } & \multirow[b]{2}{*}{$\begin{array}{l}\text { Number of MWNT-7 } \\
\text { (fibers/body weight:g) }\end{array}$} \\
\hline & & & $\begin{array}{l}\text { Number of MWNT-7 } \\
\text { (fibers/lung) }\end{array}$ & $\begin{array}{l}\text { Amount of MWNT-7 } \\
\text { (ug/body weight:g) }\end{array}$ & \\
\hline \multicolumn{6}{|l|}{ Male } \\
\hline 0 & 2 & - & - & - & - \\
\hline 0.02 & 2 & 10.0 & $0.09 \times 10^{9}$ & 0.029 & $0.26 \times 10^{6}$ \\
\hline 0.2 & $16 *$ & 152.4 & $1.38 \times 10^{9}$ & 0.434 & $3.92 \times 10^{6}$ \\
\hline 2 & $22 * *$ & 1797.8 & $16.2 \times 10^{9}$ & 4.954 & $44.7 \times 10^{6}$ \\
\hline \multicolumn{6}{|l|}{ Female } \\
\hline 0 & 0 & - & - & - & - \\
\hline 0.02 & 2 & 8.1 & $0.07 \times 10^{9}$ & 0.034 & $0.31 \times 10^{6}$ \\
\hline 0.2 & 0 & 118.4 & $1.07 \times 10^{9}$ & 0.453 & $4.09 \times 10^{6}$ \\
\hline 2 & $16^{* *}$ & 1154.1 & $10.4 \times 10^{9}$ & 4.712 & $42.5 \times 10^{6}$ \\
\hline
\end{tabular}

Number of MWNT-7: 1 ug $=9.03 \times 10^{6}$ (calculated by SEM)

Significant difference; *: $p \leqq 0.05 * *: p \leqq 0.01$ by Fisher Exact test 
A

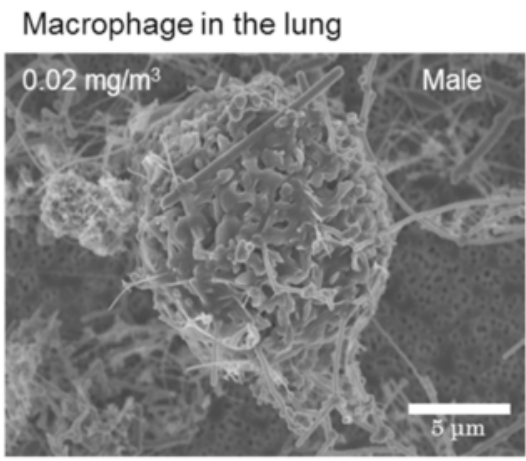

C

Pleural lavage fluid

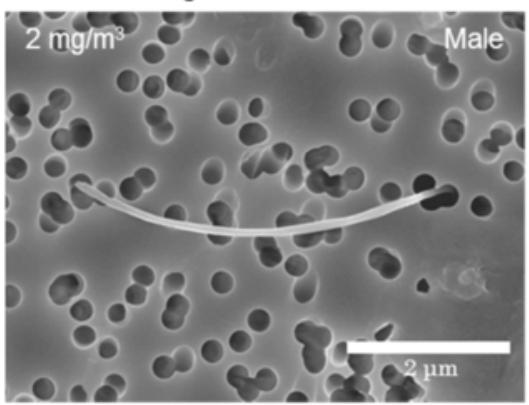

B

Lysis of macrophage in the lung

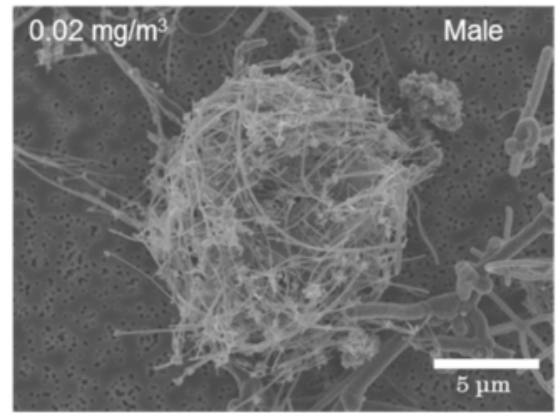

D

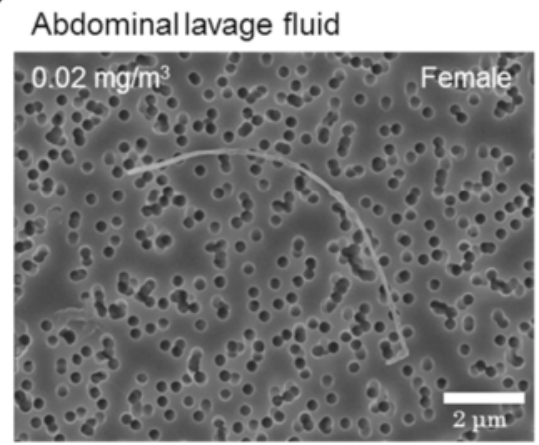

Fig. 7 SEM image of alveolar macrophages and MWNT-7 in the lung, and MWNT-7 in the pleural or abdominal fluid. a An incompletely digestion alveolar macrophage from the lung of a male rat exposed to $0.02 \mathrm{mg} / \mathrm{m}^{3}$ MWNT-7. b After complete digestion of macrophages, large cocoon-like masses of fibers were observed. The spacemen was collected from the lung of a male rat exposed to $0.02 \mathrm{mg} / \mathrm{m}^{3}$ MWNT-7. c MWNT-7 from the pleural fluid. The morphology of the MWNT-7 fiber is single and straight. d MWNT-7 from the abdominal fluid. The morphology of the MWNT-7 fiber is single and straight

support this length hypothesis: the mean length of MWNT-7 collected from the lungs of exposed rats in the present study was 5.8-5.9 $\mu \mathrm{m}$.

In the present inhalation study, the number of MWNT-7 fibers in the lung needed for inducing lung carcinoma was over $1 \times 10^{9}$ fibers. Rittinghausen et al. [2] reported intraperitoneal injection of $1 \times 10^{9}$ or $5 \times$ $10^{9}$ MWCNT fibers resulted in tumor incidences of 40 and $100 \%$, respectively. These two results suggest that large amounts of MWCNT are needed to induce the development of malignant tumors.

Total lung burden (Deposited lung dose) is calculated as Exposure concentration $\times$ Minute ventilation $\times$ Exposure duration $\times$ Alveolar deposition fraction. The MWNT-7 deposited in the lungs of male rats exposed to $0.02,0.2$, and $2 \mathrm{mg} / \mathrm{m}^{3}$ MWNT-7 resulted in total lung burdens of approximately $0.01,0.15$, and $1.8 \mathrm{mg}$ (Table 4), respectively. Using an average minute ventilation for male rats of $186 \mathrm{ml} / \mathrm{min}$ [32] and an exposure duration of $6 \mathrm{~h} /$ day $\times$ 492 days, the deposition fraction was calculated as roughly 1.5-2.7 \%.

To begin to assess possible effects of human exposure to MWNT-7 in the workplace, we calculated the correlation of rodent to human exposure in accordance with the report of Kuempel and Erdely [33, 34]: Human lung burden equals rat lung burden $(0.01,0.15$, and $1.8 \mathrm{mg}) \times$ Human alveolar surface area $\left(102 \mathrm{~m}^{2}\right)$ / rat alveolar surface area $\left(0.4 \mathrm{~m}^{2}\right)$, resulting in approximate equivalent whole lung burdens of 2.6, 38.3, and $459 \mathrm{mg}$ in humans. Assuming (1) human ventilation is $20 \mathrm{~L} / \mathrm{min}$ during light work, (2) exposure for $8 \mathrm{~h}$ per day, 5 days per week, 52 weeks per year, over a working lifetime of 45 years, and (3) a deposition efficiency of $4 \%$, then lung burdens of 2.6, 38.3, and $459 \mathrm{mg}$ in humans would require that workers are exposed to concentrations of $0.6,8.5$, and $102.2 \mu \mathrm{g} / \mathrm{m}^{3} \mathrm{MWNT}-7$ : human lung burden equals (airborne MWNT-7 concentration) $\times(20 \mathrm{~L} /$ $\min \times 10^{-3} \mathrm{~m}^{3} / \mathrm{L} \times 60 \mathrm{~min} / \mathrm{h} \times 8 \mathrm{~h} / \mathrm{d} \times 5 \mathrm{~d} /$ week $\times 52$ weeks/year $\times 45$ years) $\times 4 \%$. Of note, a worker exposed to a concentration of $8.5 \mu \mathrm{g} / \mathrm{m}^{3}$ can expect an approximate lung deposition of $38.3 \mathrm{mg}$, which is equivalent to a lung burden of $150 \mu \mathrm{g}$ in rats, a lung burden that resulted in development of lung carcinoma in male rats. Values of $0.6,8.5$, and $102.2 \mu \mathrm{g} / \mathrm{m}^{3}$ are within the range of reported workplace exposures with measured total gravimetric mass concentrations of MWCNT ranging 
from 0.7 to $332 \mu \mathrm{g} / \mathrm{m}^{3}$ in personal breathing zones [35-37].

The amount of MWNT-7 retained in the lungs increased with concentration, and the development of pre-neoplastic and neoplastic lesions in the lungs also increased with concentration. This is consistent with the premise that biopersistence is an important factor in fiber-dependent generation of neoplasias [30]. This may also explain the requirement for the large amounts of MWCNT that are needed to induce the development of malignant tumors.

In our previous study, we observed large aggregates of MWNT-7 in alveolar macrophages [21, 22], and in the present study large aggregates of MWNT-7 were also observed in digested alveolar macrophages. These aggregates were composed of MWNT-7 fibers that wound around each other forming large dense cocoonlike shaped masses approximately $10-20 \mu \mathrm{m}$ in diameter (Fig. 7b). The formation of these masses is most likely due to the structural flexibility of MWNT-7. There was a concentration-dependent increase in the number of these masses in the lung tissue. The increase of undigested MWNT-7 s with increased exposure time demonstrates the possibility of a continuous, extended reaction against these fibers: the persistence of phagocytosed indigestable materials have been reported to be associated with production of high levels of ROS and inflammatory cytokines [38-41]. In addition, Donaldson et al. [30] reported that frustrated phagocytosis by macrophages attempting to enclose long fibers leads to prolonged release of cytokines and oxidants.

The presence of large aggregates of MWNT-7 fibers in alveolar macrophages is likely to be a source of intracellular stress, even if they do not explicitly demonstrate incomplete phagocytosis (Fig. 7b). Fractured alveolar macrophages in the proximal alveolar space were also found in the present study. Our results suggest that not only the length but also the quantity of MWNT-7 fibers is important in the pulmonary toxicity of MWNT-7. Overall, our results support the paradigm that biopersistence of fibers such as MWNT-7 leads to persistent generation of oxidants and cytokines, which in turn leads to continuous inflammation, and that inflammation can lead to the development of hyperplastic lesions (Table 3) that have the potential to develop into malignant tumors (Table 3 ).

There was a gender difference in the development of pre-neoplastic and neoplastic lesions in MWNT-7exposed rats: exposure to $0.2 \mathrm{mg} / \mathrm{m}^{3}$ MWNT-7 resulted in development of lung tumors in males but not females. The lung weights of the males and females were 1.51 and $1.14 \mathrm{~g}$, respectively (Table 2), and the number of MWNT7 fibers in the whole lung of males and females exposed to $0.2 \mathrm{mg} / \mathrm{m}^{3}$ MWNT-7 was $1.38 \times 10^{9}$ and $1.07 \times 10^{9}$ fibers, respectively (Table 4). Consequently, the number of MWNT-7 fibers per lung weight $(\mathrm{g})$ in males and females was $0.91 \times 10^{9}$ and $0.94 \times 10^{9}$, respectively. These results indicate that there was not a relationship between the number of fibers per gram of lung and the gender difference in tumor development in the present study. However, the historical control data our institute has complied from the control groups of inhalation carcinogenicity studies conducted over the past 10 years, shows that the incidence of spontaneous bronchiolo-alveolar tumors in F344 rats is higher in males than in females (bronchioloalveolar adenoma: 35/599 males and 14/600 females, bronchiolo-alveolar carcinoma: 6/599 males and 0/550 females). Therefore, the difference in the sensitivity between males and females exposed to MWNT-7 is likely to be due to gender differences in their basic susceptibility to the development of lung tumors.

Sargent et al. [19] reported that MWNT-7 inhalation exposure at $5 \mathrm{mg} / \mathrm{m}^{3}$ for 15 days using mice pretreated with methylcholanthrene (a tumor initiator) increased incidences of bronchiolo-alveolar tumors in the lungs at 17 months post-exposure. However, exposure of MWNT7 without an initiator did not increase the incidences of lung tumors in their study. Consequently, they concluded that MWNT-7 s have a promoter effect in mouse lung carcinogenesis. In contrast, in our study, exposure of rats to MWNT-7 for 104 weeks without a tumor initiator induced development of lung carcinomas. These two results suggest that not only amounts of MWNT-7 but also exposure duration have important roles in lung carcinogenesis mediated by MWNT-7. Additionally, it is likely that the mouse is less susceptible to particle induced carcinogenesis than the rat, as previous investigations of rodent exposure have shown that exposure to asbestos by inhalation or intratracheal instillation is strongly carcinogenic in the rat lung but only weakly carcinogenic in the mouse [42-44].

There was no induction of pleural mesothelioma, however, there was a concentration-dependent increase of proliferative lesions, such as mesothelial hyperplasia in the parietal pleura, in both males and females. Notably, the number of MWNT-7 fibers in the pleura of the $2 \mathrm{mg} / \mathrm{m}^{3}$ MWNT-7 exposed groups was $1 \times 10^{3}$ fibers, $10^{6}$ fold lower than the number of fibers needed to result in tumor formation in the lung. The considerable difference in fiber number between the lung and the pleura likely accounts for the difference in tumor induction in these organs. Recently it was reported that pleural mesotheliomas were induced in rats administered MWCNT (NIKKISO, Tokyo, Japan) at a dose of $1 \mathrm{mg}$ over a 2-week period by intratracheal instillation and then followed for 2 years without any treatment [45]. Further studies are required to determine the reason for the different results obtained from administration using inhalation and intratracheal instillation. 
Straight MWCNT fibers and asbestos are thought to have similar physical characteristics, such as a long and thin form (i.e., high aspect ratio) and high mechanical strength, although the chemical surface properties are different. Male rats exposed to asbestos by inhalation developed lung tumors and mesothelioma [46, 47]. Histopathological classification of the lung tumors were adenoma, adenocarcinoma, squamous cell carcinoma, and unclassified lung carcinoma. Biopersistence of asbestos fibers is a primary factor in the toxic effects exerted by asbestos [30, 48]. The results of asbestos studies and our study point to a similarity between MWNT-7 and asbestos hazard, supporting previous predictions of the risk of MWCNT fibers to exposed humans [30].

The determination of whether a genotoxic or nongenotoxic mechanism operates in MWNT-7 induced carcinogenicity is important for carcinogen risk assessment. In an in vitro study, Ames tests of MWNT-7 were negative, indicating that MWNT-7 is not a direct DNA mutagen [49]. In contrast, using eukaryotic cells positive results for MWNT-7 genotoxicity were obtained: Ema et al. [49] and Asakura et al. [50] reported that MWNT-7 genotoxicity was characterized by formation of polyploidy without structural chromosomal aberration; Asakura et al. [50] reported increased numbers of bi- and multi-nucleated cells without micronucleus induction; Yasui et al. [51] observed that comparatively long MWNT-7 (approximately $\geq 20 \mu \mathrm{m}$ ) inhibited cytokinesis during cell division and induced the formation of binucleated cells, whereas short MWNT-7 did not. Interestingly, Kato et al. [52] reported that MWNT-7 induced micronucleus formation and sister chromatid exchange. Taken together, these results indicate that MWNT-7 does not induce mutations through direct interaction with the DNA (negative results in Ames tests) but rather through direct interference with biological processes during cytokinesis. In addition, Kato et al. [52] report that intratracheal instillation of MWNT-7 in mice increased gpt mutation frequencies, DNA damage by comet assay, and DNA oxidative damage. This type of damage is consistent with damage due to oxidative stress and inflammatory responses, but gpt mutations and oxidative damage are not consistent with aberrant cytokinesis. Therefore, these results suggest that the genotoxicity of MWNT-7 in vivo is due to secondary mechanisms such as oxidative stress and inflammatory responses.

Because of the differences in fiber length, shape, and rigidity of different MWCNTs, factors that are likely to be crucial in the development of tumors, the present study does not apply to all MWCNTs. However, based on MWNT-7, a fibrous MWCNT, having a carcinogenic potential, it is important to consider the risk to humans of exposure to rigid MWCNTs with a similar length and width.

Based on animal experimental studies, IARC [53] evaluated MWNT-7 as being a possible carcinogen to humans (Group 2B). NIOSH (2013) [54] proposed an 8-h timeweighted average concentration of $1 \mu \mathrm{g} / \mathrm{m}^{3}$ as the Recommended Exposure Limit (REL) for the respirable mass fraction of elemental carbon, single or multi-walled carbon nanotubes, and carbon nanofibers.

For risk analysis, a point of departure (PoD) from the observed carcinogenesis data should be estimated to mark the beginning of extrapolation to lower doses. The lower confidence limits of the benchmark dose yielding a response with a $10 \%$ extra risk $\left(\mathrm{BMCL}_{10}\right)$ were calculated with US.EPA's benchmark dose software Version 2.6 (US.EPA, 2015) [55]. In the present study, induction of lung carcinoma in male rats was observed at $0.2 \mathrm{mg} /$ $\mathrm{m}^{3}$ MWNT-7 and the BMCL 10 of adverse effect in exposed male rats was calculated to be $0.01 \mathrm{mg} / \mathrm{m}^{3}$.

MWNT-7 is classified as a genotoxicic substance but not directively DNA-reactive [49-52], and it has been accepted that there are thresholds for carcinogens that induce mutations via secondary genotoxic mechanisms $[56,57]$. Consequently, MWNT-7 may be considered to have a threshold of carcinogenicity.

The no observed adverse effect level (NOAEL) for carcinogenicity of MWNT-7 in this study was $0.02 \mathrm{mg} /$ $\mathrm{m}^{3}$ since exposure to this level of MWNT-7 did not result in the development of lung carcinomas in male rats. The chronic toxicity of MWNT-7, the lowobserved-adverse-effect level (LOAEL), was $0.02 \mathrm{mg} / \mathrm{m}^{3}$ since absolute and relative lung weights were significantly elevated in female rats exposed to $0.02 \mathrm{mg} / \mathrm{m}^{3}$ MWNT-7.

\section{Conclusions}

There is clear evidence of MWNT-7 carcinogenicity in male and female F344 rats exposed to MWNT-7 aerosol by inhalation for 104 weeks. Lung carcinomas were significantly increased in male rats by exposure to 0.2 and $2 \mathrm{mg} / \mathrm{m}^{3}$ MWNT-7 and in female rats by exposure to $2 \mathrm{mg} / \mathrm{m}^{3}$ MWNT-7. Combined adenoma and carcinoma in the lung were also significantly increased by exposure of male rats to 0.2 and $2 \mathrm{mg} / \mathrm{m}^{3} \mathrm{MWNT}-7$ and by exposure of female rats to $2 \mathrm{mg} / \mathrm{m}^{3} \mathrm{MWNT}-7$. Finally, pre-neoplastic epithelial lesions were also significantly increased by exposure of male rats to 0.2 and $2 \mathrm{mg} / \mathrm{m}^{3}$ MWNT-7 and by exposure of female rats to $2 \mathrm{mg} / \mathrm{m}^{3}$ MWNT-7. The induction of carcinomas and combined carcinomas and adenomas was dosedependent in male rats, and the induction of preneoplastic epithelial lesions was dose-dependent in both males and females. 
Induction of plural mesothelioma by exposure to MWNT-7 was not observed in this study. However, simple mesothelial hyperplasia and focal fibrosis in the parietal pleura were found in rats exposed to $2 \mathrm{mg} / \mathrm{m}^{3}$ MWNT-7.

In the studies reported to date, including this one, three factors stand out as crucial for induction of tumors by exposure to MWNT-7: (1) length, (2) biopersistence, and (3) quantity of fibers in the exposed tissue. One likely factor in the lack of mesothelioma development in the MWNT-7 exposed rats is the low number of MWNT-7 fibers in the pleura: $1.38 \times 10^{9}$ and $10.4 \times 10^{9}$ fibers were found in the lungs of the $0.2 \mathrm{mg} / \mathrm{m}^{3}$ MWNT-7 exposed males and the $2 \mathrm{mg} / \mathrm{m}^{3}$ MWNT-7 exposed females, respectively, while only on the order of $1 \times 10^{3}$ fibers were found in the pleura of the $2 \mathrm{mg} / \mathrm{m}^{3}$ MWNT-7 exposed animals.

\section{Methods}

Test substance

The MWCNT (MWNT-7; Lot No. 080126 until 88 weeks, Lot No. 071223 from 89 weeks) was purchased from Hodogaya Chemical, Co. Ltd. (Tokyo, Japan). This MWNT-7 was used without further purification or sieving. According to Hodogaya Chemical, Co. Ltd, the MWNT-7 fibers were generated using a floating chemical vapor deposition (CVD) process with a carbon purity of > $99.6 \%$ (No. 071223) and > $99.8 \%$ (No. 080126), a nominal average diameter of 40 to $90 \mathrm{~nm}$, an aspect ratio of greater than 100 , and a surface area of $24-28 \mathrm{~m}^{2} / \mathrm{g}$. We previously reported our analysis of MWNT-7 using LA-ICP-MAS: iron, chromium and nickel in MWNT-7 were 4400, 48, and $17 \mathrm{ppm}$, respectively [58].

The length and width of bulk MWNT-7, the MWNT-7 in the inhalation chambers, and the MWNT-7 in the lungs was measured using SEM at magnifications of $\times 5000$ and $\times 10,000$ in our institute. The lengths of 1000 and the widths of 500 bulk MWNT-7 fibers were measured using a curvimeter and scale loupe on enlarged SEM-photographs. The lengths and widths of 200 MWNT-7 fibers collected from the inhalation chambers and 200 MWNT-7 fibers collected from the lungs at the end of the experimental period were measured using the SEM's image analysis software. Bulk MWNT-7, lot No. 071223, fibers had an average width of $83.8 \mathrm{~nm}$ and length of $5.2 \mu \mathrm{m}$, with $45.1 \%$ of the tubules being longer than $5 \mu \mathrm{m}$. Bulk MWNT-7, lot No. 080126, fibers had an average width of $90.7 \mathrm{~nm}$ and length of $5.7 \mu \mathrm{m}$, with $48.7 \%$ of the tubules being longer than $5 \mu \mathrm{m}$. The MWNT-7 fibers collected from the inhalation chamber had an average with of 92.9-98.2 nm and length of 5.4-5.9 $\mu \mathrm{m}$. The MWNT-7 fibers found in the lung had an average width of 95.5-109.6 nm and length of $5.8-5.9 \mu \mathrm{m}$.

\section{Animals}

We used two-hundred F344/DuCrlCrlj rats of each sex purchased from Charles River Japan Inc. (Kanagawa, Japan) at 4 weeks of age. The animals were quarantined and acclimated for 2 weeks before the commencement of the experiment (exposure started at 6 weeks of age). The animals were divided by stratified randomization into 4 body weight-matched groups of 50 rats of each sex for exposure to $0,0.02,0.2$, or $2 \mathrm{mg} / \mathrm{m}^{3}$ MWNT-7. During the acclimation and exposure periods, rats were housed individually in stainless-steel wire hanging cages $(150 \mathrm{~W} \times 216 \mathrm{D} \times 176 \mathrm{H} \mathrm{mm})$ placed in pyramid-shaped stainless steel inhalation exposure chambers $\left(10 \mathrm{~m}^{3}\right.$ in volume). Throughout the experimental period including quarantine, acclimation, and exposure, all animals had free access to sterilized water and gamma-irradiationsterilized commercial pellet diet (CRF-1, Oriental Yeast Co. Ltd., Tokyo, Japan). Fluorescent lighting was controlled automatically to give a 12-h light/dark cycle.

This study was conducted in accordance with the Organisation for Economic Co-operation and Development (OECD) Guideline for Testing of Chemicals 451 "Carcinogenicity Studies" (OECD, 2009) [23] and with "Standards to be Observed by Testing Institutions" Notification No. 76 of the Ministry of Labour, Japan, 1 September 1988 (amendment: Notification No. 13 of the Ministry of Labour, Japan, 29 March 2000) and with the OECD Principles of Good Laboratory Practice (OECD, 1981) [59]. This study was approved by the Animal Experiment Committee of the Japan Bioassay Research Center. Animal care and was conducted in accordance with the Guideline for proper conduct of Animal Experiments (Science Council of Japan, 2006).

\section{Environment in the inhalation chamber and MWNT-7 exposure design}

Throughout the 104-week experimental period, the ventilation flow rate of the inhalation chamber was maintained at $1.67 \mathrm{~m}^{3} / \mathrm{min}$, corresponding to 10 changes/hour, and the chamber temperature and humidity were set at $22 \pm$ $2{ }^{\circ} \mathrm{C}$ and $50 \pm 20 \%$. The inhalation chamber environmental parameters were monitored every minute with sensors for airflow, temperature (Shimaden, Co. Ltd., Tokyo, Japan), and humidity (NGK Spark Plug, Co., Ltd., Nagoya, Japan).

Groups of 50 rats of each sex were exposed to MWNT-7 aerosol for 104 weeks (6 h/day, 5 days/week) at target concentrations of $0,0.02,0.2$, or $2 \mathrm{mg} / \mathrm{m}^{3}$. Our facility is large enough to accommodate the 400 animals used in this study, therefore all of the rats were exposed at the same time. The MWNT-7 concentrations used in this inhalation exposure study were decided on the basis of the results of our previous 13- 
week inhalation study using MWNT-7 concentrations of $0,0.2,1$, and $5 \mathrm{mg} / \mathrm{m}^{3}$ [22].

\section{Aerosol generation and inhalation exposure to MWNT-7} The aerosol generation method (cyclone sieve method) of Kasai et al. [20-22] was used to generate MWNT-7 aerosols. We have developed an aerosol generator that dry-aerosolizes MWNT-7 with an upward spiraling airstream, classifies particles by gravitational and centrifugal forces, limits particle size with a sieve, and provides the inhalation chamber with a size-limited MWNT-7 aerosol (Additional file 1: Figure S1). The aerosol generator is composed of an aerosol generation and sieving unit, a concentration control unit, ionizers (Keyence Corporation, Tokyo, Japan), and a touch panel data recording device for data collection. The aerosol generation and sieving unit consists a cylindrical container with a partitioning sieve (Seishin, Co. Ltd., Tokyo, Japan) and a solenoid impactor. The concentration control unit consists of an optical particle controller (OPC, OPC-AP-600, Sibata Scientific Technology, Ltd., Tokyo, Japan) and a dust feeder (Type FO, Funken Powtechs, INC,Tokyo, Japan). The dust feeder introduces bulkMWNT-7 (Fig. 8) into the mid-portion of the cylindrical container. Clean air is aspirated from nine diagonally-opened slits installed at the bottom of the cylinder by utilizing ejector air with a flow rate of $100 \mathrm{~L} /$ minute as the driving force, so that an upward spiraling airstream is continuously generated. Bulk MWNT-7 is dispersed and aerosolized by collision of the MWNT-7 with the high-speed upward spiraling airstream provided from the slits. Shear forces within the cyclone as well as in the ejector also contribute to dispersion. Light MWNT-7 particles are carried to the top of the cylindrical container, where a partitioning sieve is located, riding on the upward spiraling airstream and selectively passing through the pores of the sieve $(53 \mu \mathrm{m})$. Heavy MWNT-7 particles spiral around under the sieve, agglomerate by the centrifugal force generated by the upward spiraling airstream, and finally fall down into the collection flask. Pulse vibration generated by a solenoid impactor prevents MWNT-7 clogging of the partitioning sieve pores. Ionizers are deployed to prevent adsorption onto walls of the system's components and to prevent self-assembly of MWNT-7 aerosols.

\section{Monitoring and regulation of MWNT-7 aerosol in the inhalation chamber}

Chamber atmosphere samples were taken from the animals' breathing zone. Monitoring and regulation of MWNT-7 aerosols in the inhalation exposure chambers is described in detail by Kasai et al. [20-22]. Particle concentrations of MWNT-7 in the chambers were monitored in real-time with an optical particle controller $(\mathrm{OPC})$. The OPC data were collected every $10 \mathrm{~s}$. The mass-concentrations of MWNT-7 were determined gravimetrically by collecting aerosols on Teflon-binder filters for each target exposure concentration after 1,3 , or $5 \mathrm{~h}$ of exposure once every 2 weeks throughout the experimental period. The mass per particle (the $\mathrm{K}$ value) was calculated based on the particle concentration data (particles $/ \mathrm{m}^{3}$ ) collected by the OPC and the gravimetric results $\left(\mathrm{mass} / \mathrm{m}^{3}\right)$. Using this K-value, particle concentrations were converted to mass-concentrations every 30 min for each group during the exposure periods. The chamber MWNT-7 concentrations were held constant by controlling the movement of the dust feeder using a feedback loop from the OPC: when the chamber concentration rose above the upper limit of a designated concentration range, the dust feeder stopped supplying MWNT-7 aerosol to the sieving unit and when the chamber concentration fell below the lower limit, the

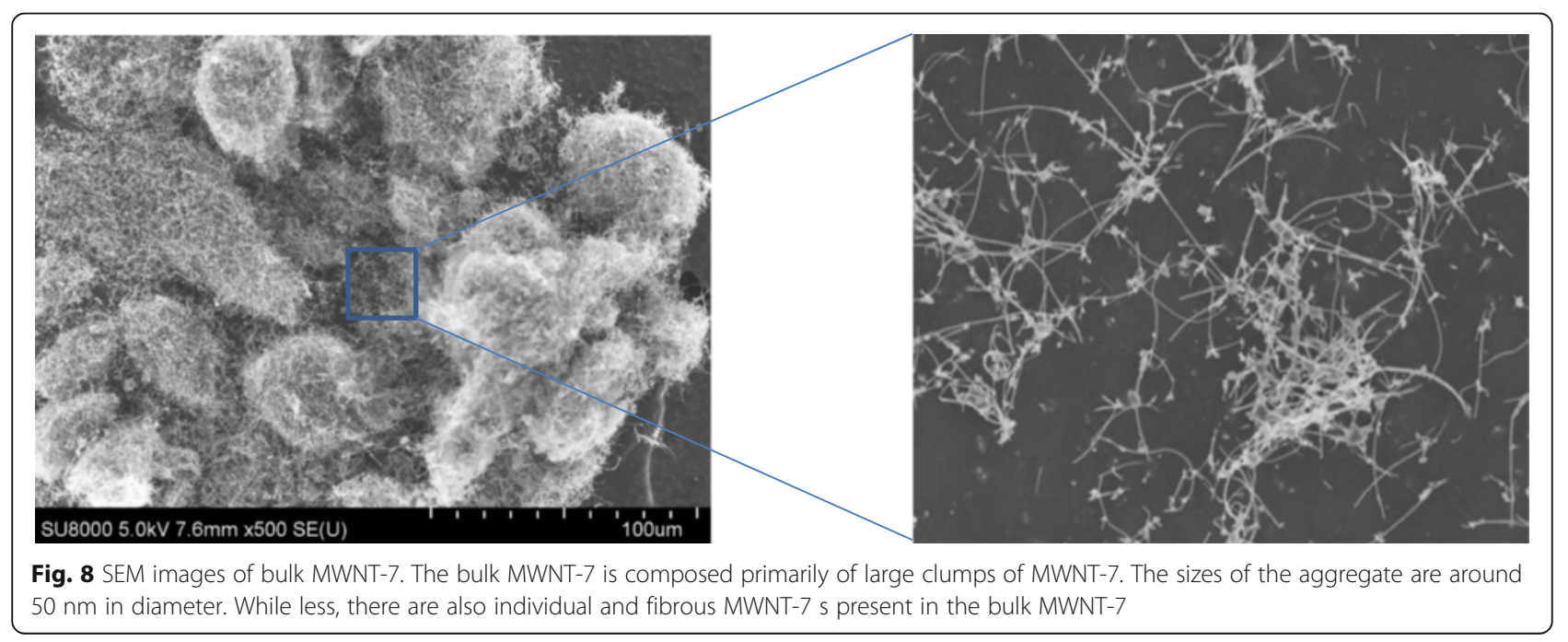


dust feeder resumed supplying MWNT-7 aerosol to the sieving unit. The size distribution and morphology of the MWNT-7 fibers was determined nine times over the course of 13 weeks throughout the experimental period. The size distribution of the fibers was ascertained using a micro-orifice uniform deposit cascade impactor (MOUDI) (Model 125B NanoMoudi-II, MSP, Shoreview, MN, USA), and the morphology of the fibers was examined by SEM (SU8000, Hitachi Ltd., Tokyo, Japan).

\section{Clinical observations and urinary, hematological, and blood biochemical analyses}

The animals were observed daily for clinical signs and mortality. Body weight and food consumption were measured once a week for the first 14 weeks and every 4 weeks thereafter. Urinary parameters were measured in the last week of the 104-week experimental period with Ames Reagent Strips (Multistix, Siemens Healthcare Diagnostics, Tokyo, Japan). At the terminal necropsy, blood was collected for hematology and blood biochemistry from the abdominal aorta under isoflurane anesthesia after overnight fasting. The blood sample was analyzed with an automatic blood cell analyzer (ADVIA120, Siemens Healthcare Diagnostics Inc. Tarrytown, NY, USA) and an automatic analyzer (Hitachi 7080, Hitachi, Ltd., Ibaraki, Japan) for blood biochemistry.

\section{Organ weights and macroscopic and microscopic examinations}

Organs, including the adrenal, testis, ovary, heart, lung (except for lungs collected for BALF analysis), kidney, spleen, liver and brain, were collected at the terminal necropsy and weighed and examined for macroscopic lesions. To avoid contamination of MWNT-7, animals from each administration group were anatomized separately. After macroscopic examination the nasal cavity, nasopharynx, larynx, trachea, lungs, bone marrow, lymph nodes (including lung associated lymph nodes), thymus, spleen, heart, tongue, salivary gland, esophagus, stomach, small intestine, large intestine, liver, pancreas, kidneys, urinary bladder, pituitary gland, thyroid, parathyroid, adrenal glands, testis, epididymis, seminal vesicle, prostate, ovaries, uterus, vagina, mammary gland, brain, spinal cord, peripheral nerve, olfactory bulb, eye, Harderian gland, muscle, bone, and diaphragm (as a part of the parietal pleura) were examined histopathologically. For histopathological examination, the tissues were fixed in $10 \%$ neutral buffered formalin and embedded in paraffin. The right lung was directly fixed by immersion. The left lung including the BALF collected rats was inflated with fixative at a water pressure of $20-25 \mathrm{~cm}$, and then fixed by immersion. The nasal cavity was decalcified in a formic acid-formalin solution and then transversely trimmed at three levels as previously described $[21,60]$. Tissue sections of all organs, including the right lung and left lung, of $5 \mu \mathrm{m}$ in thickness were prepared and stained with hematoxylin and eosin (H \& E) (Additional file 2: Table S1). To detect MWNT-7 s deposited in the larynx, trachea, lungs, pleura (diaphragm), lymph nodes, spleen, liver, kidneys, olfactory bulb, and brain, sections were stained with Kernechtrot stain (Merck, Darmstadt, Germany) for $1 \mathrm{~min}$ and washed with distilled water for $5 \mathrm{~min}$.

\section{Cytological and biochemical analyses of the BALF}

At the end of the experimental period, five animals from each group were lavaged (Additional file 2: Table S1). The right bronchus was tied with a thread in order to lavage only the left lung. The lung was lavaged 2 times with $5 \mathrm{ml}$ Eagle's Minimum Essential Medium (MEM, adjusted pH7.2 with $1 \mathrm{~N} \mathrm{NaOH}$ and $15 \mathrm{mM}$ HEPES without sodium hydrogen carbonate) for males and $4 \mathrm{ml}$ for females at a water pressure of $20-25 \mathrm{~cm}$ (the epithelium is peeled by washing with higher pressure or by washing more than twice). The wash-out was collected for cytological and biochemical analysis and the lung tissue was processed for histopathological examination as described above. The cells in the BALF were counted with an automatic cell analyzer (Sysmex fully automated hematology analyzers XT-2000iv). For biochemical analysis, the BALF was centrifuged at $1960 \mathrm{rpm}(800 \mathrm{~g})$ at $4{ }^{\circ} \mathrm{C}$ for $10 \mathrm{~min}$, and aliquots of the acellular supernatant were examined with an automatic analyzer (Hitachi 7080, Hitachi, Ltd., Ibaraki, Japan). Total protein (TP), lactate dehydrogenase (LDH), and alkaline phosphatase (ALP) levels were measured by conventional biochemical methods. TP was chosen as an indicator of alveolo-capillary permeability while LDH and ALP were used as indicators of general cytotoxicity and type II epithelial cell toxicity, respectively.

\section{MWNT-7 lung burden}

Lung burden analysis was determined for dead and euthanized animals (Additional file 2: Table S1): 7, 7, and 6 males and 12, 8, and 11 females from the $0.02,0.2$, and $2 \mathrm{mg} / \mathrm{m}^{3}$ MWNT-7-exposed groups, respectively. At terminal necropsy, lung burden was determined for 10 MWNT-7-exposed animals from each group (Additional file 2: Table S1). Lungs were weighed and then prepared for histopathological examination; remaining right lung tissue (0.04-0.12 g) was used for lung burden analysis. For determination of lung burden, lung tissue was digested according to the method of Kohyama et al. [61], and filtered to obtain dry specimens. MWNT-7 measurement was performed according to the method of Ohnishi et al. [62]. Lung burden was determined as the MWNT-7 value in the analyzed lung tissue multiplied by the ratio of total lung weight/analyzed lung weight. The amounts of 
MWNT-7 per whole lung and per gram body weight were determined. For determination of the number of MWNT-7 fibers in the lung, one $\mu$ g bulk MWNT-7 was suspended in $100 \mathrm{ml}$ distilled water containing $0.1 \%$ Tween 80 as a colloidal dispersant and subjected to ultrasonication for $30 \mathrm{~min}$ with an ultrasonic homogenizer (VP-30S, $20 \mathrm{kHz}, 300 \mathrm{~W}$, TAITEC Co. Ltd, Tokyo, Japan). A polycarbonate membrane filter (Isopore, Millipore, MA, USA) pre-coated with Pt for electron charge avoidance was positioned on a suction filtration apparatus, and $10 \mu \mathrm{l}$ of the MWNT-7 suspension was placed on the filter and dried by suction. After drying, an area equal to $1 \%$ of whole filter was subjected to field emission SEM. The MWNT-7 fibers on the filter were photographed for counting at a magnification of $\times 2000$. The number of fibers in one- $\mu \mathrm{g}$ MWNT-7 were calculated from the dilution ratio and area ratio of the filter. The total number of MWNT-7 fibers in the lungs was calculated as the number of fibers in one- $\mu \mathrm{g}$ of MWNT-7 multiplied by the $\mu \mathrm{g}$ of MWNT-7 in the lung.

\section{Observation of MWNT-7 in the lung}

To observe MWNT-7 in the lung, lung tissues were digested according to the method of Kohyama et al. [61]. The lung tissues were left for 5 days in the digestion solution. The solution was then filtered and specimens collected on polycarbonate membrane filters (Isopore, Millipore, MA, USA) pre-coated with Pt for electron charge avoidance. The specimens were observed by SEM.

\section{Measurement of number MWNT-7 pleural and abdominal lavage fluid}

At terminal necropsy, the pleural cavity of ten animals was lavaged once with $8 \mathrm{ml} \mathrm{MEM}$, and the abdominal cavity of ten other animals was lavaged once with $40 \mathrm{ml}$ MEM. The washout was collected and centrifuged at $12,000 \mathrm{rpm}(3000 \mathrm{~g})$ at $15^{\circ} \mathrm{C}$ for $10 \mathrm{~min}$. The supernatant was removed and the pellet was digested according to the method of Kohyama et al. [61]. A polycarbonate membrane filter (Isopore, Millipore, MA, USA) pre-coated with Pt for electron charge avoidance was positioned on a suction filtration apparatus, and MWNT-7 fibers were collected onto the filter. The morphology of the fibers was determined by SEM examination, and the number of MWNT-7 fibers was counted.

\section{Statistics}

Incidences of neoplastic lesions were analyzed for a dose response relationships by Peto's test [63] and for a significant difference from the clean air-exposed group by Fisher's exact test. Incidences of non-neoplastic lesions and urinary parameters were analyzed by the Chi-square test. Survival curves were plotted according to the method of Kaplan-Meier [64], and the log-rank test [65] was used to detect statistically significant differences in survival rates between any MWNT-7 exposed groups of either sex and the clean air-exposed group. Body weight, organ weight, food consumption, hematology, blood biochemical parameters, and biochemical and cytological parameters in the BALF were analyzed by Dunnett's multiple comparison test. Two-tailed tests were used for all statistical analyses except for Peto's test. $P$ values less than 0.05 were considered to be statistically significant.

\section{Additional files}

Additional file 1: Figure S1. Blue arrows indicate the flow of the MWNT-7. Red arrows indicate aerosolization of the MWNT-7 by the upward spiraling airstream. MWNT-7 (Bulk MWNT-7) is first placed into the dust feeder. The dust feeder transports a portion of the MWNT-7 into the sieving chamber (Left panel). In the sieving chamber, clean air is aspirated from 9 diagonally opened slits by using the ejector air as the driving force, so that an upward spiraling airstream is continuously generated in the cylindrical sieving chamber. MWNT-7 is dispersed and aerosolized by the high-speed spiraling air. Light MWNT-7 particles are carried to the top of the sieving chamber, where a partitioning sieve is located. Only the sieved MWNT-7 can be delivered to the inhalation chamber. lonizers are used to avoid agglomeration. This equipment has a feedback system for keeping the aerosol concentration in the inhalation chamber constant. (PPS $2292 \mathrm{~kb}$ )

Additional file 2: Table S1. Number of Rats Examined for Lung Histopathology, BALF and Lung Burden. (XLSX $13 \mathrm{~kb}$ )

\section{Abbreviations}

ALP: Alkaline phosphatase; BALF: Bronchoalveolar lavage fluid; BALT: Bronchus-associated lymphoid tissue; CNT: Carbon nanotube; CVD: Chemical vapor deposition; GSD: Geometric standard deviation; H\&E: Hematoxylin and eosin; HPLC: High performance liquid chromatography; LDH: Lactate dehydrogenase; MHLW: Ministry of Health Labour, and Welfare; MMAD: Mass median aerodynamic diameter; MOUDI: Micro-orifice uniform deposit cascade impactor; MTD: Maximum tolerated dose; MWCNT: Multi-walled carbon nanotube; OECD: Organisation for Economic Co-operation and Development; OPC: Optical particle controller; PAH: Polycyclic aromatic hydrocarbon; SEM: Scanning electron microscope; TP: Total protein

\section{Acknowledgements}

We are deeply indebted to all members of the committee, set up in the Japan Industrial Safety \& Health Association (chaired by Dr. Hidesuke Shimizu, Professor Emeritus of The Jikei University School of Medicine and Director of Occupational Health Research and Development Center, Japan Industrial Safety and Health Association), for overseeing the project from the building of the aerosol generation system to the carcinogenesis study of nanomaterials using rats and for their warm encouragement and fruitful discussions throughout the present study. Advice and comments given by Dr. Hyogo Horiguchi (Professor in the Kitasato University School of Medicine), Dr. Masashi Tsunoda (Associate professor in the Kitasato University School of Medicine) and Dr. Naohide Shinohara (National Institute of Advanced Industrial Science and Technology) were a great help. We wish to thank Dr. David B. Alexander (Nanotoxicology Project, Nagoya City University) for his valuable comments and advice. We also gratefully acknowledge the technical support of all members in our institute, especially Mr. Tadao Toya, Mr. Shigeyuki Hirai, and Mr. Masahiro Yamamoto.

\section{Funding}

The present studies were contracted and supported by the Ministry of Health, Labour and Welfare of Japan. The authors declare that they have no conflicts of interest. 


\section{Availability of data and material}

Data sharing not applicable to this article as no datasets were generated or analysed during the current study.

\section{Authors' contributions}

TK conceived the study, operated the employed system, directed the implementation of the MWNT-7 toxicity examinations, analyzed the experimental results, and drafted and wrote the manuscript. YU carried out the MWNT-7 pathological examinations, analyzed the experimental results, and assisted in drafting and writing the manuscript. MO provided important information on pulmonary MWNT-7 measurement and determined the MWNT7 lung burden. TM contributed to the analysis of the data and assisted in analysis of the experimental results. HK performed the hematology, blood biochemical and BALF examinations, and contributed to the analysis of the data. $T$ took charge of animal management and welfare, and assisted in writing the manuscript. MM contributed to study design, performed the statistical analysis, and assisted in writing the manuscript. SF contributed to the study design, acquisition of funding, implementation of the MWNT-7 study, writing the manuscript, headed the project, and gave the final approval of the version to be published. All authors read and approved the final manuscript.

\section{Competing interests}

The authors declare that they have no conflicts of interest.

\section{Consent for publication}

Not applicable.

\section{Ethics approval and consent to participate}

This study was approved by the Animal Experiment Committee of the Japan Bioassay Research Center. Animal care and was conducted in accordance with the Guideline for proper conduct of Animal Experiments (Science Council of Japan, 2006).

\section{Received: 7 April 2016 Accepted: 30 September 2016}

Published online: 13 October 2016

\section{References}

1. Endo M. Grow carbon fibers in the vapor phase. In: CHEMTECH. American Chemical Society. 1988. http://www.kroto.info/wp-content/uploads/2015/ 10/2.Chemtech1988.pdf. Accessed 2 Mar 2016.

2. Rittinghausen $\mathrm{S}$, Hackbarth $A$, Creutzenberg $O$, Ernst $H$, Heinrich $U$, Leonhardt A, et al. The carcinogenic effect of various multi-walled carbon nanotubes (MWCNTs) after intraperitoneal injection in rats. Part Fiber Toxicol. 2014; doi:10.1186/s12989-014-0059-z.

3. Mercer RR, Scabilloni JF, Hubbs AF, Wang L, Battelli LA, McKinney W, et al. Extrapulmonary transport of MWCNT following inhalation exposure. Part Fibre Toxicol. 2013; doi:10.1186/1743-8977-10-38.

4. Stanton MF, Layard M, Tegeris A, Miller E, May M, Morgan E, et al. Relation of particle dimension to carcinogenicity in amphibole asbestoses and other fibrous minerals. J Natl Cancer Inst. 1981;67:965-75

5. Mcdonald JC, Armstrong B, Case B, Doell D, McGaughey WTE, Mcdonald $A D$, et al. Mesothelioma and asbestos fiber type. Evidence from lung tissue analyses. Cancer. 1989;63:1544-7.

6. Donaldson K, Murphy FA, Duffin R, Poland DC. Asbestos, carbon nanotubes and the pleural mesothelium: a review of the hypothesis regarding the role of long fibre retention in the parietal pleura, inflammation and mesothelioma. Part Fibre Toxicol. 2010; doi:10.1186/1743-8977-7-5.

7. Henderson DW, Jones ML, de Klerk N. After Helsinki: a multidisciplinary review of the relationship between asbestos exposure and lung cancer, with emphasis on studies published during 1997-2004. Pathology. 2004;36:517-50

8. Tomatis L, Cantoni S, Carnevale F, Merler E, Mollo F, Ricci P, et al. The role of asbestos fiber dimensions in the prevention of mesothelioma. Int J Occup Environ Health. 2007;13:64-9.

9. Boulanger G, Andujar P, Pairon JC, Billon-Galland MA, Dion C, Dumortier P, et al. Quantification of short and long asbestos fibers to assess asbestos exposure: a review of fiber size toxicity. Environ Health. 2014; doi:10.1186/1476-069X-13-59.

10. Poland CA, Duffin R, Kinloch I, Maynard A, Wallace WAH, Seaton A, et al. Carbon nanotubes introduced into the abdominal cavity of mice show asbestos-like pathogenicity in a pilot study. Nature Nanotechnol. 2008;3:423-8.

11. Takagi A, Hirose A, Nishimura T, Fukumori N, Ogata A, Ohashi N, et al. Induction of mesothelioma in p53+/- mouse by intraperitoneal application of multi-wall carbon nanotube. J Toxicol Sci. 2008;33:105-16.

12. Sakamoto Y, Nakae D, Fukumori N, Tayama K, Maekawa A, Imai K, et al. Induction of mesothelioma by a single intrascrotal administration of multi-wall carbon nanotube in intact male Fischer 344 rats. J Toxicol Sci. 2009;34:65-76.

13. Nagai H, Okazaki Y, Chew SH, Misawa N, Yamashita Y, Akatsuka S, et.al. Diameter and rigidity of multiwalled carbon nanotubes are critical factors in mesothelial injury and carcinogenesis. PNAS. 2011; doi:10.1073/pnas.1110013108.

14. Takagi A, Hirose A, Futakuchi M, Tsukada H, Kanno J. Dose-dependent mesothelioma induction by intraperitoneal administration of multi-wall carbon nanotubes in p53 heterozygous mice. Cancer Sci. 2012;103:1440-4.

15. Dahm MM, Schubauer-Berigan MK, Evans DE, Birch ME, Fernback JE, Deddens JA. Carbon nanotube and nanofiber exposure assessments: an analysis of 14 site visits. Ann Occup Hyg. 2015;59:705-23.

16. Takaya M, Serita F, Ono-Ogasawara M, Shinohara Y, Saito H, Koda S. Airborne particles in a multi-wall carbon nanotube production plant: Observation of particle emission and personal exposure I: Measurement in the packing process. JPN J Ind Health (San Ei Shi). 2010;52:182-8 (In Japanese).

17. Ryman-Rasmussen JP, Cesta MF, Brody AR, Shipley-Phillips JK, Everitt J, Tewksbury EW, et al. Inhaled carbon nanotubes reach the subpleural tissue in mice. Nature Nanotechnol. 2009:4:747-51.

18. Poter DW, Hubbs AF, Chen TB, McKinny W, Mercer RR, Wolfarth MG, et al. Acute pulmonary dose-responses to inhaled multiwalled carbon nanotubes. Nanotoxicology. 2012;7:1179-94.

19. Sargent LM, Porter DW, Staska LM, Hubbs AF, Lowry DT, Battelli L, et al. Promotion of lung adenocarcinoma following inhalation exposure to multi-walled carbon nanotubes. Part Fibre Toxicol. 2014; doi:10.1186/ 1743-8977-11-3.

20. Kasai T, Gotoh K, Nishizawa T, Sasaki T, Katagiri T, Umeda Y, et al. Development of a new multi-walled carbon nanotube (MWCNT) aerosol generation and exposure system and confirmation of suitability for conducting a single-exposure inhalation study of MWCNT in rats. Nanotoxicology. 2014;8:169-78.

21. Umeda $Y$, Kasai T, Saito M, Kondo H, Toya T, Aiso S, et al. Two-week toxicity of multi-walled carbon nanotubes by whole-body inhalation exposure in rats. J Toxicol Pathol. 2013;26:131-40.

22. Kasai T, Umeda Y, Ohnishi M, Kondo H, Takeuchi T, Aiso S, et al. Thirteenweek study of toxicity of fiber-like multi-walled carbon nanotubes with whole-body inhalation exposure in rats. Nanotoxicology. 2015;9:413-22.

23. Organisation for Economic Cooperation and Development. OECD guideline for testing of chemicals 451 "Carcinogenicity Studies." Adopted September 2009. Paris: OECD; 2009.

24. Mclnnes EF, Miller RA. A review of upper respiratory tract inhalation pathology. Comparative Clinic Path. 2007;16:215-22.

25. Dungworth DL, Ernst H, Nolte T, More U. Nonneoplastic lesions in the lung. In: Mohr U, Dungworth DL, Capen CC, editors. Pathology of the aging rats, vol. 1. Washington DC: ILSI press; 1992. p. 143-60.

26. Renne R, Brix A, Harkema J, Herbert R, Kittel B, Lewis D, et al. Proliferative and nonproliferative lesions of the rat and mouse respiratory tract. Toxicol Pathol. 2009;37:5S-73S.

27. Dungworth DL, Hahn FF, Nikula KJ. Noncarcinogenic responses of the respiratory tract to inhaled toxicants. In: McClellan RO, Henderson RF, editors. Concepts in inhalation toxicology. 2nd ed. Washington DC: Taylor \& Francis; 1995. p. 533-76.

28. Bannasch P, Griesemer RA, Anders F, Becker R, Cabral JR, Della PG, et al. Long-term assays for carcinogenicity in animals. In: Montesano R, Bartsch H, Vainio H, Wilbourn J, Yamasaki H, editors. Long-term and short-term assays for carcinogens: A critical appraisal, 83. Lyon: IARC Scientific Publications; 1986. p. 13-83.

29. Sontag JM, Page NP, Saffiotti U. Guidelines for carcinogen bioassay in small rodents: NCI-CG-TR-1. Washington DC: DHEW; 1976.

30. Donaldson K, Poland CA, Murphy FA, MacFarlane M, Chermova T, Schinwald A. Pulmonary toxicity of carbon nanotubes and asbestos - similarities and differences. Adv Drug Deliv Rev. 2013;65:2078-86.

31. Muller J, Delos M, Panin N, Rabolli V, Huaux F, Lison D. Absence of carcinogenic response to multi-wall carbon nanotubes in a 104-week bioassay in the peritoneal cavity of the rat. Toxicol Sci. 2009;110:442-8. 
32. Bide RW, Armour SJ, Yee E. Allometric respiration/body mass data for animals to be used for estimates of inhalation toxicity to young adult humans. J Appl Toxicol. 2000;20:273-90.

33. Kuempel ED. Carbon nanotube risk assessment: implications for exposure and medical monitoring. J Occup Environ Med. 2011;53:S91-7.

34. Erdely A, Dahm M, Chen BT, Zeidler-Erdely PC, Fernback JE, Birch ME, et al. Carbon nanotube dosimetry: from workplace exposure assessment to inhalation toxicology. Part Fibre Toxicol. 2013; doi: 10.1186/1743-8977-10-53.

35. Han JH, Lee EJ, Lee JH, So KP, Lee YH, Bae GN, et al. Monitoring multiwalled carbon nanotube exposure in carbon nanotube research facility. Inhal Toxicol. 2008;20:741-9.

36. Lee JH, Lee SB, Bae GN, Jeon KS, Yoon JU, Ji JH, et al. Exposure assessment of carbon nanotube manufacturing workplaces. Inhal Toxicol. 2010;22:369-81.

37. Maynard AD, Baron PA, Foley M, Shvedova AA, Kisin ER, Castranova V. Exposure to carbon nanotube material: aerosol release during the handling of unrefined single-walled carbon nanotube material. J Toxicol Environ Health A. 2004:67:87-107.

38. Pulskamp K, Diabate S, Krug HF. Carbon nanotubes show no sign of acute toxicity but induce intracellular reactive oxygen species in dependence on contaminants. Toxicol Lett. 2007;168:58-74.

39. Sohaebuddin SK, Thevenot PT, Baker D, Eaton JW, Tang L. Nanomateria cytotoxicity is composition, size, and cell type dependent. Part Fibre Toxicol. 2010; doi: 10.1186/1743-8977-7-22.

40. Xu J, Futakuchi M, ligo M, Fukamachi K, Alexander DB, Shimizu H, et al. Involvement of macrophage inflammatory protein 1a (MIP1a) in promotion of rat lung and mammary carcinogenic activity of nanoscale titanium dioxide particles administered by intra-pulmonary spraying. Carcinogenesis. 2010;31:927-35.

41. Ma-Hock L, Strauss V, Treumann S, Küttler K, Wohlleben W, Hofmann T, et al. Comparative inhalation toxicity of multi-wall carbon nanotubes, graphene, graphite nanoplatelets and low surface carbon black. Part Fibre Toxicol. 2013; doi:10.1186/1743-8977-10-23.

42. Mauderly $\mathrm{JL}$. Relevance of particle-induced rat lung tumors for assessing lung carcinogenic hazard and human lung cancer risk. Environ Health Perspect. 1997;105:1337-46.

43. Reeves AL, Puro HE, Smith RG, Vorwald AJ. Experimental asbestos carcinogenesis. Environ Res. 1971;4:496-511.

44. Yee H, Yie TA, Goldberg J, Wong KM, Rom WN. Immunohistochemical study of fibrosis and adenocarcinoma in dominant-negative p53 transgenic mice exposed to chrysotile asbestos and benzo(a)pyrene. J Environ Pathol Toxicol Oncol. 2008;27:267-76

45. Suzui M, Futakuchi M, Fukamachi K, Numano T, Abdelgied M, Takahashi S, et al. Multiwalled carbon nanotubes intratracheally instilled into the rat lung induce development of pleural malignant mesothelioma and lung tumors. Cancer Sci. 2016; doi: 10.1111/cas.12954.

46. Davis JM, Addison J, Bolton RE, Donaldson K, Jones AD, Smith T. The pathogenicity of long versus short fibre samples of amosite asbestos administered to rats by inhalation and intraperitoneal injection. $\mathrm{Br} J$ Exp Pathol. 1986;67:415-30.

47. Davis JM, Jones AD. Comparisons of the pathogenicity of long and short fibres of chrysotile asbestos in rats. Br J Exp Pathol. 1988:69:717-37.

48. Mossman BT, Lippmann M, Hesterberg TW, Kelsey KT, Barchowsky A, Bonner JC. Pulmonary end points (lung carcinomas and asbestosis) following inhalation exposure to asbestos. J Toxicol Env Heal B. 2011;14:76-121.

49. Ema M, Imamura T, Suzuki H, Kobayashi N, Naya M, Nakanishi J. Evaluation of genotoxicity of multi-walled carbon nanotubes in a battery of in vitro and in vivo assays. Reg Toxi Pharm. 2012;63(2):188-95.

50. Asakura M, Sugiyama T, Sasaki T, Takaya M, Koda S, Nagano K, et al. Cytotoxicity and mutagenicity of multi-wall carbon nanotubes in cultured Chinese hamster lung cells. J Occup Health. 2010;52:155-66.

51. Yasui M, Kamoshita N, Nishimura T, Honma M. Mechanism of induction of binucleated cells by multiwalled carbon nanotubes as revealed by live-cell imaging analysis. Genes Environ. 2015; doi: 10.1186/s41021-015- 0003-y.

52. Kato $T$, Totsuka $Y$, Ishino $K$, Matsumoto $Y$, Tada $Y$, Nakae D, et al. Genotoxicity of multi-walled carbon nanotubes in both in vitro and in vivo assay systems. Nanotoxicology. 2013;7:452-61.

53. Benbrahim-Tallaa L, Guha N, Bouvard V, Carel R, Ghissassi F El, Grosse Y, et al. Carcinogenicity of fluoro-edenite, silicon carbide fibres and whiskers, and carbon nanotubes. Lancet Oncol. 2014. http://impactitalia.gov.it/binary/ pres/cont/111_Grosse_nanotubes.pdf.
54. National Institute for Occupational Safety and Health (NIOSH). Current intelligence bulletin 65. Occupational exposure to carbon nanotubes and nanofibers. US Department of Health and Human Services Centers for Disease Control and Prevention, DHHS (NIOSH) Pub. No. 2013-145. Cincinnati: NIOSH; 2013. https://www.cdc.gov/niosh/docs/2013-145/pdfs/ 2013-145.pdf.

55. United States Environmental Protection Agency (US.EPA). Benchmark dose software version 2.6 user's manual. EPA100/R-12/001. Washington, DC: US EPA; 2015.

56. Bolt HM, Degen GH. Human carcinogenic risk evaluation, part II: contributions of the EUROTOX specialty section for carcinogenesis. Toxico Sci. 2004;81:3-6.

57. Fukushima S, Wei M, Kakehashi A, Wnibuchi H. Threshold for genotoxic carcinogen: evidence from mechanism-based carcinogenicity studies. Cancer risk assessment. 2010. doi: 10.1002/9780470622728.ch8.

58. Takaya M, Serita F, Yamazaki K, Aiso S, Kubota H, Asakura M, et al. Characteristics of multiwall carbon nanotubes for an intratracheal instillation study with rats. Ind Health. 2010;48:452-9.

59. Organisation for Economic Cooperation and Development. OECD principles of good laboratory practice. Adopted 1981. Paris: OECD; 1981

60. Nagano K, Katagiri T, Aiso S, Senoh H, Sakura Y, Takeuchi T. Spontaneous lesions of nasal cavity in aging F344 rats and BDF1 mice. Exp Toxicol Pathol. 1997:49:97-104.

61. Kohyama N, Suzuki Y. Analysis of asbestos fibers in lung parenchyma, pleural plaques, and mesothelioma tissues of North American insulation workers. Ann NY Acad Sci. 1991;643:27-52.

62. Ohnishi M, Yajima H, Kasai T, Umeda Y, Yamamoto M, Yamamoto S, et al. Novel method using hybrid markers: development of an approach for pulmonary measurement of multi-walled carbon nanotubes. J Occup Med Toxicol. 2013; doi: 10.1186/1745-6673-8-30

63. Peto R, Pike MC, Day NE, Gray RG, Lee PN, Parish S, et al. Annex Guidelines for simple, sensitive significance tests for carcinogenic effects in long-term animal experiments: Long-term and short-term screening assays for carcinogens: a critical appraisal. IARC Monographs 1980: Suppl 2:311-426.

64. Kaplan EL, Meier P. Nonparametric estimation from incomplete observations. Am Stat Assoc J. 1958:53:457-81.

65. Peto R, Pike MC, Armitage P, Breslow NE, Cox DR, Howard SV, et al. Design and analysis of randomized clinical trials requiring prolonged observation of each patient. II. Analysis examples. Br J Cancer. 1977;35:1-39.

\section{Submit your next manuscript to BioMed Central and we will help you at every step:}

- We accept pre-submission inquiries

- Our selector tool helps you to find the most relevant journal

- We provide round the clock customer support

- Convenient online submission

- Thorough peer review

- Inclusion in PubMed and all major indexing services

- Maximum visibility for your research

Submit your manuscript at www.biomedcentral.com/submit
) Biomed Central 